\title{
Business fluctuations in a behavioral switching model: gridlock effects and credit crunch phenomena in financial networks
}

\author{
Ruggero Grilli \\ Department of Managment, Università Politecnica delle Marche, Ancona, 60122, Italy \\ r.grilli@univpm.it \\ Gabriele Tedeschi ${ }^{*}$ \\ Department of Economics, Universidad Jaume I, Castellon, 12071 Spain \\ gabriele.tedeschi@gmail.com \\ Mauro Gallegati \\ Department of Managment, Università Politecnica delle Marche, Ancona, 60122, Italy \\ mauro.gallegati@univpm.it
}

February 15, 2020

\begin{abstract}
In this paper we characterize the evolution over time of a credit network in the most general terms as a system of interacting banks and firms operating in a threesector economy with goods, credit and interbank market. Credit connections change over time via an evolving fitness measure depending from lenders' supply of liquidity and borrowers' demand of credit. Moreover, an endogenous learning mechanism allows agents to switch between a loyal or a shopping-around strategy according to their degree of satisfaction. The crucial question we investigate is how financial bubbles and credit-crunch phenomena emerge from the implemented mechanism.
\end{abstract}

Keywords: business fluctuations; financial frictions; switching behavior; fitness model; dynamic credit network.

\footnotetext{
*corresponding author: gabriele.tedeschi@gmail.com. Department of Economics, Universidad Jaume I, Castellon, 12071 Spain, Ph.:(+34) 964728612 — Fax (+34) 964728591.
} 


\section{Introduction}

The interdependence between real and financial markets has a long tradition in Economics. The literature has particularly focused on which of these two markets drives business fluctuations and economic growth. The main research question was to understand if it was the real economy to foster finance sectors or, alternatively, the credit market to stimulate real production. In other words, the economic research has always sought to capture the driving-force generating expansions and contractions of economic and financial cycles, that is to seize the direction of the causality nexus. Although theoretical and empirical studies diverge in identifying the direction of the causality nexus, with the pre-Lehman studies identifying the direction from real markets to financial sectors (see Bernanke and Gertler, 1989; Greenwald and Stiglitz, 1993; Kiyotaki and Moore, 1997), while the post-Lehman ones reversing it (see Christiano and Ikeda, 2011: Brunnermeier et al., 2012), what is certainly undoubted is the self-reinforcing interaction between the two sectors which translates into booms followed by busts (see Borio, 2014). Yet, when credit boom bubbles go burst the macroeconomic consequences are severe (see Jordà et al., 2015, Mishkin, 2008). The interaction, in fact, is seen as the key ingredient in the cycles' onset (see, Grilli et al., 2017, for a survey of the relevant literature). In whatever way this is modeled, either via balance-sheets interconnectedness among intermediaries (see Adrian and Shin, 2010a b, 2011; Geanakoplos, 2010, Gertler and Kiyotaki, 2010), or more sophisticated network theory tools (see Glasserman and Young, 2015, Lageras and Seim, 2016; Acemoglu et al., 2013; Battiston et al., 2007, 2012b a; Bargigli and Tedeschi, 2014), the interaction among banks and firms represents the channel to propagate/reduce financial frictions among market participants (see, Gertler and Williamson, 2015, for a collection of articles on this topic).

Following the pioneering financial accelerator framework by Bernanke and Gertler (1989) and Kiyotaki and Moore (1997), many attempts to model financial frictions and study their impact on financial and real markets have been proposed (see Carlstrom and Fuerst, 1997; Bernanke et al., 1999, among the first attempts). All these studies have identified some possible driving-force able to amplify and propagate the conventional transmission mechanism of real and monetary shocks through the endogenous emergence of limits on the available quantity of external finance. In this regard, an interesting branch of literature has focused on coordination failure mechanisms as a possible explanation of the emergence of credit frictions. Specifically, this literature has shown that the strategic behavior of heterogenous interacting agents competing for the achievement of scarce financial resources gives rise to spillovers and strategic complementarities leading to coordination failure phenomena (see Rajan, 1994, Aikman et al., 2015, Bassetto et al., 2015). Following this line of research, in this paper we are interested in identifying an endogenous mechanism able to generate coordination failure and analyzing its repercussions at micro and macro level. In this regard we build a three sector economy with goods, credit and interbank market, where agents, banks and firms, strategically compete for allocating their financial resources on an evolving credit network. On the one hand firms, operating as borrowers in the credit market, compete in seeking the best 
credit conditions in order not to be rationed. On the other hand banks, operating as lenders in the credit market and as lenders or borrowers in the interbank one, compete in offering the best credit conditions in term of interest rates and supply of liquidity when lenders, while they behave as the companies do when borrowers. The credit linkages between borrowers and lenders might change over time via a preferential attachment evolving procedure such that each borrower can enter into a lending relationship with lenders with a probability proportional to a compound fitness measure. This measure is a combination between lender attractiveness (i.e its fitness) in terms of supply of liquidity and interest rates and the borrower satisfaction (i.e its intensity of choice) in terms of credit requirements fulfillment. Lenders, therefore, can attract their customers by offering a high supply of liquidity associated with a low interest rate and borrowers reinforce the lender signal when their credit requirements are met. Moreover, the conduct of debtors which strengthen / weaken their creditors' attractiveness on the basis of the granted loan, generates switching behavior in this group of agents. On the one hand, customers who meet their credit needs become loyal to their lenders and strengthen the intensity of choice parameter. On the other hand, those agents who are rationed become shoppers-around and weaken the intensity of choice parameter. The co-movement between the intensity of choice and the fitness is able to reproduce different credit network topologies ranging from the random graph to the scale-free one. This evolutionary framework allows us to emphasize the effect of different agents' strategies and different network architectures on the business fluctuations.

In line with the results of the above mentioned studies on strategic complementarities, this work shows that a strong coordination in the agents' behavior may generate a highly centralized credit network and this produces gridlock effects in the credit market and the emergence of credit crunch phenomena. An intuition of how the credit network architecture influences business fluctuation is as follows. Our system crosses several steps in the credit network evolution corresponding to the different strategies adopted by borrowers and lenders. There are times governed by the shopping around strategy, where the lender attractiveness is very low and, therefore, the credit network is random. Poor economic performances are associated with these periods because agents remain small in size and, consequently, the demand of credit and the production are low. As time goes by, some financial institutions gain credibility in the market and become more attractive in term of supply of liquidity and interest rates. This reinforces the fitness of these lenders which can attract several clients and ensure their loyalty. The heterogeneity of agents, therefore, increases the fitness signal and moves borrowers to choose the loyal strategy which is associated with a lower rationing. This process leads to the emergence of exponential or scale-free credit network topologies. At the same time, macroeconomic conditions improve, the credit allocation becomes more efficient and the production increases. Gradually, the system tends to create a large financial institution (i.e. hub) to which many loyal clients are connected. Obviously, this high centrality in the credit network, after an initial period where the hub can meet clients' credit needs, leads to gridlock effects and credit crunch phenomena. The hub, unable 
to satisfy its clients loses its attractiveness, the credit bubbles go bust, the aggregate output collapses. Consequently, the system returns to a random credit network with shopping around agents.

Interestingly enough, our approach in explaining the materialization of financial frictions is very close in spirit to the Minskyan financial instability hypothesis, where endogenous shifts on the degree of financial fragility of banks generate business fluctuations (see Minsky, 1964; Ferri and Minsky, 1992). In fact, we show that swings in banks' leverage are associated with the sequence of life stages that financial institutions undergo, from small decentralized entities to too-big centralized hubs. By combining the heterogenous agents approach with an endogenous mechanism generating time-varying financial relationships, we can show that the two main ingredients explaining the evolution of risk, namely the agents' financial fragility and the direct or indirect interconnections among market participants, are far from being independent and, actually co-evolve.

Our stylized mechanism, designed to combine micro behaviors with meso financial interlinkages and macro performances, extends the theoretical literature dealing with the relationship between connectivity, business and financial cycles and systemic instability in dynamic credit networks (see, Grilli et al., 2017, for a survey of this literature). In this regard, the contribution of this work in respect to this literature is twofold. First, to our knowledge, this is the only study introducing in a three sectors economy, the dynamic evolution of credit and interbank networks jointly. In fact, models with goods, credit and interbank markets just consider random graph credit systems where, by exogenously changing the degree of connectivity among agents, the system reproduces the well-known trade-off between systemic and sharing risk (see Grilli et al., 2014, 2015, Tedeschi et al., 2012b). On the contrary, the literature dealing with evolutionary networks, just focuses attention on two-sectors' systems composted by firm-bank, firm-firm or bank-bank credit relationships (see, for instance, Delli Gatti et al., 2010, 2009, Berardi and Tedeschi, 2017).

Second, among these last mentioned studies modeling dynamic credit linkages, the originality of this work is in the inclusion of a reinforcement mechanism between the lender fitness and the borrower intensity of choice. Specifically, the "endogenization" of the intensity of choice allows us, on the one hand, to solve the well-known calibration problems associated with this parameter (see Recchioni et al., 2015; Kukacka and Barunik, 2017, for technical details), and, on the other hand, to introduce competition both on lender and borrower side.

Last but not least, the problems arising from credit market interconnectedness have also been highlighted by empirical studies which have emphasized the effect of preferential trading relationships on credit availability (see Boot, 2000, Ongena and Smith, 2000; $\mathrm{Pe}-$ tersen and Rajan, 1994, Vidal et al., 2019). Although we do not want to enter into the debate on (dis)advantages of enduring credit relations, our results certainly support a vast literature sustaining privileged credit relationships as a tool to mitigate asymmetric information problems. However, we show that these relationships must be established with small local financial institutions (Presbitero et al., 2014, Strahan and Weston, 1998, 
Avery and Samolyk, 2004; Berger and Frame, 2007; Berger and Black, 2011), and do not have to generate too-big or/and too-interconnected hubs.

The rest of the paper is organized as follows. In Section 2 we describe the model by analyzing the behavior of firms and banks and the dynamic of the credit and interbank network. In Section 3 we present the results of the simulations. Specifically, we proceed in two steps: firstly, we present the performances of agents and investigate how they influence the evolution of the financial network; secondly, we study the impact of the different network topologies on business fluctuations. Finally, Section 4 concludes.

\section{The model}

We consider a three-sector economy with goods, credit and interbank market. The system is populated by two constant classes of agents - firms and banks - who undertake decisions at discrete time $t=1, \ldots, T$.

In the good market, firms produce an homogeneous output by adopting a linear technology with capital as the only input. Due to informational imperfections on the equity market, the capital stock evolves according to investment expenditure which in turn depend on the firms' ability in raising funds on the credit market. The role of the financial system is twofold. First, it allows companies to finance their production plans. Second, this is the only instrument banks have in order to earn profits. In fact, our financial institutions, modeled as risk neutral agents, try to satisfy all the credit requests received by their clients, by charging a risk premium on the interest rate which is proportional to the borrower financial fragility. In other words, banks try to transform all their available liquidity 1 into credit supply which is sold at the zero-profit interest rate. In the adverse event the bank liquidity supply is not enough to meet the firm credit demand, financial institutions can enter in the interbank market. Here, the main purpose is to re-allocate the available liquidity from banks in surplus to those in deficit. Thanks to this market, therefore, borrower banks do not lose the opportunity to satisfy the credit requests of firms and, lender banks can benefit from an extra profit coming from the granting loan to borrowers.

Essentiality, the financial system as a whole is represented by two interconnected evolving networks: the credit and the interbank market. In the former, players are firms acting as borrowers and banks as lenders, while in the later financial institutions are the only players acting as borrowers or lenders as needed. The whole interaction mechanism consists in a strategic evolutionary game, where lenders try to attract clients by offering all the available liquidity at the cheapest interest rate and borrowers try to avoid credit rationing phenomena. In this "struggle for credit", borrowers can strengthen / weaken their trust relationship with the lender on the basis of their credit claim satisfaction. Specifically, by means of a simple reinforcement-learning mechanism, borrowers receiving a positive feedback (i.e. pleased with their credit claim) maintain a stable lending

\footnotetext{
${ }^{1}$ The only constrain financial institutions face in the credit allocation is the "minimum leverage requirement" imposed by the Basel III regulatory framework.
} 
relationship with their lender and play the loyal strategy, while those receiving a negative feedback try to cut their credit relationship and play the shopping-around strategy. In each period the strategies are updated and players can switch behavior, accordingly ${ }^{2}$.

\section{Firms}

In what follows, we describe the basic ingredients of the good market. For more technical details on firms' behavior in this market we refer the reader to Delli Gatti et al. (2005).

Technology available to the $i$-th firm $(i=1,2, \ldots, N)$ in period $\mathrm{t}$ is represented by a linear production function:

$$
Y_{i, t}=\phi K_{i, t}
$$

where $K_{i, t}$ is the capital stock and $\phi$ its constant productivity. The firm sets the optimum quantity to be produced $Y_{i, t}^{*}$ at the beginning of each period t. Following Greenwald and Stiglitz (1993) we assume that bankruptcy is costly and the cost of bankruptcy is quadratic in output. The firm maximizes an objective function defined as expected profit less expected bankruptcy costs. The details can be found in Delli Gatti et al. (2005). The outcome of the optimization problem is the desired capital:

$$
K_{i, t}^{*}=\frac{\phi-g r_{i, j, t}^{L}}{c \phi g r_{i, j, t}^{L}}+\frac{A_{i, t-1}}{2 g r_{i, j, t}^{L}}
$$

where $r_{i, j, t}^{L}$ is the real interest rate the bank $j$ charges to the $i$-th firm, g is a parameter related to total capital costs, $g>1$, c is a parameter related to bankruptcy costs, $A_{i, t-1}$ is the net worth of the firm. Desired capital (and, therefore, desired output $Y_{i, t}^{*}=\phi K_{i, t}^{*}$ ) is increasing with net worth and decreasing with the interest rate.

Investment is defined as $I_{i, t}=K_{i, t}^{*}-K_{i, t-1}$. Hence the demand for credit is:

$$
L_{i, t}^{*}=K_{i, t}^{*}-A_{i, t-1}-\pi_{i, t-1},
$$

where $\pi_{i, t-1}$ represent the profits of the firm.

As in Greenwald and Stiglitz (1993) the goods market is fully supply driven, that is the firm can sell all the output it optimally decides to produce. Therefore, profits in real term are equal to:

$$
\pi_{i, t}=u_{i, t} Y_{i, t}-g r_{i, j, t}^{L} K_{i, t}=\left(u_{i, t} \phi-g r_{i, j, t}^{L}\right) K_{i, t},
$$

where $u_{i, t}$ is an iid idiosyncratic real shock hitting the firm demand of goods with $\mathrm{E}\left(u_{i, t}\right)=1$ and finite varianc ${ }^{3}$. The firm retains profits and adds them to equity. In other words, the equity base of the firm obeys the following law of motion:

$$
A_{i, t}=A_{i, t-1}+\pi_{i, t} .
$$

Due to the uncertainty of the environment, firm $i$ may go bankrupt when its net worth at time $t$ becomes negative, $A_{i, t} \leqslant 0$.

\footnotetext{
${ }^{2} \mathrm{~A}$ sensitivity analysis on the switching update frequency is performed in Appendix B.

${ }^{3}$ In real terms, $u_{i, t}$ represents the $i$-th selling price, which is a uniform with support $(0,2]$.
} 


\section{Banks}

The $j$-th bank $(j=1,2, \ldots, B)$ in period t operates in a competitive and arbitrage-free credit market. The bank inter-day balance sheet structure is defined as $S_{j, t}=E_{j, t}+D_{j, t}$, where $S_{j, t}, E_{j, t}$ and $D_{j, t}$ represent, respectively the total amount of liquidity, the equity and deposit of bank $j$ in time t. The primary function of the bank activity is to lend its funds through loans to firms, as this is its way to make money via interest rates. Assuming the agent risk neutrality, the bank optimal strategy is to determine the zero expected-profit interest rate to which offering a completely elastic liquidity supply. Hence the bank $j$ expected profit for a loan to $i$ is given by:

$$
E\left(\pi_{j, i, t}^{B}\right)=r_{i, j, t}^{L} L_{i, j, t}\left(1-p_{i, t}\right)-r_{j, t}^{d}\left(D_{j, t}+E_{j, t}\right),
$$

where $r_{i, j, t}^{L}$ and $L_{i, j, t}$ are the credit conditions in term of interest rate and total loan the bank $j$ applies to firm $i, p_{i, t}$ is the firm's default probability and $r_{j, t}^{d}$ the remuneration of deposits and equity.

Let us now define the parameters appearing in Eq. 6. First, the bank $j$ is willing to lend to its clients as much credit as it can (i.e all its amount of liquidity $S_{j, t}$ ), up to the limit imposed by the Basel III regulatory framework (BIS, 2010). Specifically, our financial institutions are subjected to a "minimum leverage requirement4", which implies:

$$
\frac{1}{\lambda_{j, t}^{B}}=\frac{E_{j, t}}{\left(S_{j, t}+L_{j, t}\right)} \geq 0.03
$$

with $\lambda_{j, t}^{B}$ to be the bank leverage.

Second the bank has to estimate the bankruptcy probability, $p_{i, t}$, of its client $i$. Making use of Eqs.445 and recalling that the firm may go bankrupt as soon as its net worth becomes negative, it follows that the bankruptcy state occurs whenever: $u_{i, t}=\frac{1}{\phi}\left(g r_{i, j, t}^{L}-\right.$ $\left.\frac{A_{i, t-1}}{K_{i, t}}\right) \equiv \bar{u}_{i, t}$. Consequently, assuming $u_{i, t} \sim \mathcal{U}(0,2)$, the bankruptcy probability ${ }^{5}$ of firm $i$ is:

$$
p_{i, t}=\operatorname{Pr}\left(u_{i, t} \leq \bar{u}_{i, t}\right) \begin{cases}0, & \bar{u}_{i, t} \leq 0 \\ \frac{\bar{u}_{i, t}}{2}, & 0<\bar{u}_{i, t}<2 \\ 1, & \bar{u}_{i, t} \geq 2\end{cases}
$$

Finally, the bank sets the remuneration of deposits and equity, $r_{j, t}^{d}=\bar{r}_{j, t-1}^{L}-\epsilon_{j, t}$, with $\bar{r}_{j, t-1}^{L}$ to be the average rate applied by the bank $j$ in the previous period and $\epsilon_{j, t}$ a $i i d$ random variable with support $\left(0, \bar{r}_{j, t-1}^{L}\right)$. Hence, the interest rate, $r_{i, j, t}^{L}$, satisfying the

\footnotetext{
${ }^{4}$ In other words, Eq.77 defines an upper bound to banks' total exposure, which cannot be roughly 33 times higher than their equity. Interesting enough, the maximum leverage can be also interpreted as an anti-trust measure.

${ }^{5}$ The derivation of the firm bankruptcy probability follows Delli Gatti et al. (2005).
} 
free-entry condition (i.e. $\left.E\left(\pi_{j, i, t}^{B}\right)=0\right)$ is:

$$
r_{i, j, t}^{L}=\frac{r_{j, t}^{d}\left(D_{j, t}+E_{j, t}\right)}{\left(\frac{D_{j, t}}{\left(1-\frac{1}{\lambda_{j, t}^{B}}\right)}-S_{j, t}\right)\left(1-p_{i, t}\right)} .
$$

The zero expected profit interest rate is increasing with the bank financial fragility, $\lambda_{j, t}^{B}$ and decreasing with the firm's surviving probability.

In order to complete the description of banks' strategies, it is essential to introduce the functioning of the interbank market. As already mentioned, this market enables an efficient liquidity exchange among financial institutions. All banks satisfying Eq. 7 can enter the interbank market. Specifically, financial institutions with excess liquidity enter as lenders, while those with liquidity needs as borrowers. Obviously, the use of the two financial markets modifies infra-day balance sheet structure ${ }^{6}$ of $j$, now defined as $S_{j, t}+L_{j, t}+L_{j, t}^{I}=E_{j, t}+D_{j, t}+d_{j, t}^{I}$, where $L_{j, t}$ and $L_{j, t}^{I}$ represent the total amount of loan provided in the credit and interbank market respectively, and $d_{j, t}^{I}$ the total amount of debt received in the interbank system.

The credit chain works as follow. In period $t$, the firm $i$ with a positive demand of loan, $L_{i, t}^{*}>0$, selects its lender bank 77 . If $j$ has sufficient liquidity supply, that is $S_{j, t} \geq L_{i, t}^{*}$, the loan is disbursed. Otherwise, if $j$ does not have enough liquidity supply to meet its client need, that is $S_{j, t}<L_{i, t}^{*}, j$ tries to borrow in the interbank market. Here, the bank $j$ asks to its lender financial institution, $k$, the missing amount of loan needed to satisfy its client $i$. Therefore, the demand of loan of $j$ to $k$ is $d_{j, k, t}^{I}=L_{i, t}^{*}-S_{j, t}$. As in the credit market, the lender has to define the credit conditions to be applied to its client in term of total loan and interest rate. In line with the structure of the credit system, the lender offers as much credit as it can up to the limit imposed by the modified Eq7 7 as shown in the footnote 6. With respect to the interbank interest rate, the lender bank $k$ applies a discount on its average credit rate, weighted by the risk of its client $8 j$. Specifically, the overnight rate is:

$$
r_{k, j, t}^{I}=\frac{\bar{r}_{k, t-1}^{L}-\epsilon_{k, t}}{\left(1-p_{j, t}^{B}\right)},
$$

with $\bar{r}_{k, t-1}^{L}-\epsilon_{k, t}$ to be the $k$ discounted average credit rate and $p_{j, t}^{B}$ the probability of bankruptcy of the borrower $j$. Since the risk of the borrower bank just depends on its credit relationship with firms, the lender bank $k$ assigns a default probability to its

\footnotetext{
${ }^{6}$ At the same time, this implies the following modification of the Eq. $7 . \frac{1}{\lambda_{j, t}^{B}}=\frac{E_{j, t}}{\left(S_{j, t}+L_{j, t}+L_{j, t}^{I}\right)} \geq 0.03$.

${ }^{7}$ The mechanism driving the lending linkages is explained in Sec 2

${ }^{8}$ This assumption is in line with empirical evidence showing that the overnight rate is the lowest available interest rate, and as such, it is only available to the most creditworthy institutions (see Iori et al. 2008, for instance).
} 
client $j$ in accordance with this assumption. Specifically, assuming that banks absorb the firms' bad-debt with their equity and go bankruptcy when their net worth becomes negative, $E_{j, t} \leqslant 0$, the following bankruptcy probability is applied:

$$
p_{j, t}^{B}= \begin{cases}0 & \text { if } \sum_{i \in \Theta} L_{i, j, t}<E_{j, t} \\ \frac{\sum_{i \in \Theta} p_{i, t} L_{i, j, t}}{\sum_{i \in \Theta} L_{i, j, t}} & \text { else }\end{cases}
$$

where $\Theta$ is the set of all firms bank $\mathrm{j}$ lends money to, and $L_{., j, t}$ the total amount of open credit relationships of $j$ in period $t$. In other words, Eq11 can be interpreted as follows: when the equity of $j$ is enough to cover the entire amount of loans granted to firms, the probability of bankruptcy of $j$ is zero, even if no-one of $j$ 's clients pay their debt back. Otherwise, when $j$ can default because of its clients' bad debt, its probability of bankruptcy increases with its clients' one.

At the end of each period $t$, after all credit contracts have been paid in full 9 , the generic financial institution $j$ updates its profits according to:

$$
\pi_{j, t}^{B}=\sum_{i \in \Theta} r_{i, j, t}^{L} L_{i, j, t}+\sum_{n \in \Delta} r_{j, n, t}^{I} L_{j, n, t}^{I}-\sum_{k \in \Omega} r_{j, k, t}^{I} d_{j, k, t}^{I}-r_{j, t}^{d}\left(D_{j, t}+E_{j, t}\right),
$$

where the first two terms on the right side represent revenues in the credit and interbank market, respectively, the third term are costs of the interbank borrowing and, finally, the last term the costs of deposits and equity. Bank net worth evolves according to:

$$
E_{j, t}=\pi_{j, t}^{B}+E_{j, t-1}-\sum_{i \in \Xi^{\prime}} B_{i, j, t-1}-\sum_{k \in \Xi} B_{k, j, t-1}^{b},
$$

with the last two terms on the right hand side being firms and banks' bad debts respectively 10 ,

Similar to firms, financial institutions go bankrupt when their equity at time $t$ becomes negative $E_{j, t} \leqslant 0$. The failed bank leaves the market.

When firms and banks fail, they are replaced by new entrants, which are on average smaller than incumbent:11. (see Bartelsman et al. 2005).

\footnotetext{
${ }^{9}$ This hypothesis assumes that the two systems (i.e credit and interbank) operate with the same time frequency. In fact, given the credit-oriented nature (rather than a trading-oriented one) of our interbank system, we are modeling a system operating with longer-term maturity(see, for a similar approach, Affino, 2012, BIS, 1983, Dinger and Von-Hagen, 2007). However, since the related literature places great emphasis on the short-term maturity (normally overnight) of the interbank market, in Appendix B we investigate the main performance of the model in the presence of mismatch in the markets' time scale.

${ }^{10} \mathrm{In} \mathrm{Eq}, 12, i \in \Theta$ and $n \in \Delta$ are the subset of borrowers, firms and banks respectively, able to pay their debts back to $j ; k \in \Omega$ is the subset of lenders banks, the financial institution $j$ pays its debt back. In Eq $13 i \in \Xi^{\prime}$ and $k \in \Xi$ are the subset of firms and banks unable to pay their debts back because they go bankrupt.

${ }^{11}$ Specifically, all the initialization parameters of firms and banks, as described at the beginning of Sec.
} 


\section{The formation of lending linkages in the credit and interbank network}

In this section we explain formation and evolution of credit relationships, that is the way borrowers and lenders select each others. Before describing the selection mechanism, it is important to briefly recall how the credit chain is triggered.

In order to meet their investment plans, firms seek funding from a selected group of banks in the credit market. If the contacted financial institutions do not have enough liquidity to meet their clients' needs, they enter the interbank market to borrow the missing amount of money to satisfy firms' demand. Here, the bank with financial needs selects a group of lender financial institutions which can meet its liquidity need.

In our model, therefore, the two financial systems can be described with two dynamic networks. Nodes represent agents (i.e. firms and banks) and edges are the connective links between them. Links are directional, they are created and deleted by agents who look for credit and point to the financial institution that grants loan. In general local interaction models agents interact directly with a finite number of others in the population, the so-called "neighbors". In our model the number of out-going links is constrained to be $\bar{d}$, thus borrowing agents can only get loan from few lenders. There are two important reasons behind it. On the one hand, in a highly connected random network, synchronization could be achieved via indirect links. The impact of direct credit links on the credit granting is easier to be tested in a diluted network where indirect synchronization is less likely to arise. On the other hand, by keeping a fixed connectivity, we can easily compare the performance of different market topologies to spread liquidity through the network.

Let us now describe in detail how borrowers select their lenders, that is how lending linkages are formed and evolve in the credit and interbank system. In what follow, we define with $j$ the lender and with $i$ the borrower ${ }^{12}$.

Following Bianconi and Barabási (2001) and Albert and Barabási (2002), we implement an endogenous mechanism of competition among lenders in order to attract borrowers. Specifically, lenders try to distinguish themselves via a fitness measure which is function of their liquidity and interest rate. Banks start with identical initial conditions, so that all agents have the same initial liquidity and interest rate. As time goes by, some financial institutions may become more liquid than others or offer rates lower than their competitors. As a measure of the lender attractiveness we define the fitness at time $t$ as a combination between the bank liquidity relative to the liquidity of the most liquid agent, $S_{t}^{\max }$, and its interest rate relative to that of the cheapest financial institution, $r_{t-1}^{\min }$ :

$$
\eta_{j, t}=\omega \frac{S_{j, t}}{S_{t}^{\text {max }}}+(1-\omega) \frac{r_{t-1}^{\min }}{\bar{r}_{j, t-1}} .
$$

The parameter $\omega$ in Eq. 14 represents the relative liquidity weight. With regard to the

3 (i.e. the initial value of capital, loan and net-worth for firms, and initial value of loan and net-worth for banks) are equal to the mode of the agents active agents in the market.

${ }^{12}$ It is worth noting that both firms and banks can act as borrowers in our model. Specifically, the former can borrow in the credit market, while the latter in the interbank system. However, just financial institutions can act as lenders both in credit and interbank system. 
interest rate appearing in Eq. 14, two clarifications are needed. First, when the financial institution calculates its fitness, it uses the interest rate in Eq9 for loans in the credit system or in Eq.10 for those in the interbank market. Second, since interest rates are borrower-lender specific, in Eq. $14 \bar{r}_{j, t}$ denotes the lender average interest rate.

Credit linkages between lenders and borrowers in the two financial networks evolve as follows. Each borrowing agent $i$ starts with some outgoing link with some random agents (i.e borrowing position), and possibly, if $i$ is a bank, with some incoming links from other agents (i.e lending position) ${ }^{13}$, Links are rewired at the beginning of each period, in the following way: each borrower $i$ cuts its outgoing link, with lender $j$, and forms a new link, with a randomly chosen bank $k$, with a probability

$$
\operatorname{Pr}_{t, i}=\frac{1}{1+e^{-\beta_{i, t}\left(\eta_{k, t}-\eta_{j, t}\right)}}
$$

or to keep its existing link with probability $\left(1-P r_{t, i}\right)$. Essentially the switching probability described by Eq 15 is a function of two elements. The first one is the competition in term of fitness between the two lenders. The second one is the borrower intensity of choice, $\beta_{i, t}$, which answers the question on how much borrowers trust the information about their lenders performance. Typically, dynamic network models using the switching behavior described by Eq. 15 consider an exogenous value of $\beta$. Specifically, these models show that by exogenously changing the intensity of choice parameter, credit linkages self-organize themselves into very different network architectures, ranging from random to scale-free topologies (see Lenzu and Tedeschi, 2012, Tedeschi et al., 2014, Berardi and Tedeschi, 2017). In this paper, however, we endogenize the intensity of choice parameter. This modification allows us to generate a completely endogenous network dynamic and to introduce a strategic competition also on the borrowers' side.

\section{The evolution of the borrowers' strategies}

Let us consider the generic borrower $i$ which has to decide whether keeping or cutting its existing lending relationship. We define two different borrower strategies, namely the loyal and the shopping around behavior. In the time step $t$, the agent $i$ is

a) loyal if it has maintained its lending relationship with the lender $j,(i \rightarrow j)$, for at least $t-\tau$ periods, with $\tau \geq 2$,

b) shopper around if it has cut its lending relationship with $j$ before $t-\tau$ periods.

Eq. (15) shows that the intensity of choice, $\beta_{i, t}$, is the variable the borrower controls to switch from a lender to another one. For this reason, by increasing (decreasing) $\beta_{i, t}$, the switching probability diminishes (grows), and this is linked to the loyal (shopping around) strategy. Since the borrower major concern is to avoid credit rationing, each time period, $t, i$ updates its strategy according to the feedback received from its lender.

\footnotetext{
${ }^{13}$ In detail, in the first time step of the simulation the adjacency matrix of the two networks are populated as follows: we randomly assign to each lender one borrower. Consequently, each borrower has one out-going link, while lenders equally share the list of clients.
} 
Specifically, the feedback corresponds to the average variation on the credit rationing, $\Delta \bar{R}_{i, t-\tau}$, the borrower faces in the $\tau$ previous periods. The amount of credit rationing is simply defined as the difference between the asked (i.e. $l_{i, t}^{a}$ ) and the granted (i.e. $l_{i, t}^{g}$ ) loan 14 .

$$
R_{i, t}=l_{i, t}^{a}-l_{i, t}^{g} .
$$

The borrower $i$ observing $\Delta \bar{R}_{i, t-\tau} \leq 0\left(\Delta \bar{R}_{i, t-\tau}>0\right)$ receives a positive (negative) feedback on its strategy and, consequently, reinforces (reduces) its behaviour according to the received signal. Specifically, reinforcing or weakening a strategy means modifying the value of $\beta_{i, t}$ within a discrete set of possible integer values, $0 \leq \beta_{i, t} \leq \beta^{\max }$.

Let now suppose that the agent $i$ is loyal according to the definition a) above. If, in time $t, i$ receives a positive feedback, $\Delta \bar{R}_{i, t-\tau} \leq 0$, the borrower reinforces its loyalty by setting $\beta_{i, t}=\beta_{i, t-1}+\delta$. Conversely, if $i$ receives a negative feedback, $\Delta \bar{R}_{i, t-\tau}>0$, it tries to change its strategy by decreasing the intensity of choice, $\beta_{i, t}=\beta_{i, t-1}-\delta$. Symmetrically, let us suppose that the agent $i$ is shopper around according to the definition $\mathrm{b}$ ) above. In case of a positive feedback, $i$ wants to reinforce its shopping around strategy, that is the borrower persists in changing its lender frequently, by lowering its intensity of choice, $\beta_{i, t}=\beta_{i, t-1}-\delta$. Conversely, in case of a negative feedback, the agent tries to change its shopping around strategy by increasing the intensity of choice, $\beta_{i, t}=\beta_{i, t-1}+\delta$.

In the next sessions the micro, meso and macro consequences of this simple adaptive learning mechanism are investigated.

\section{Simulations and results}

We consider an economy consisting of $N=1000$ firms and $B=50$ banks and study it over a time span of $T=2000$ periods. Each firm is initially given the same amount of capital $K_{i 0}=100$, loan $L_{i 0}=80$ and net-worth $A_{i 0}=20$. We fix $\phi=0.1, g=1.7$ and $c=1$. Similarly to firms, financial institutions start with the same initial conditions. Specifically, the amount of liquidity is $S_{j 0}=\nu \cdot L_{i 0} \cdot N$, the initial loan $L_{j 0}=\left(L_{i 0} \cdot N\right) / B$, the net-worth $E_{j 0}=\nu \cdot L_{i 0} \cdot N$, with $\nu=0.08$, and the deposit $D_{j 0}=S_{j 0}+L_{j 0}-E_{j 0}$. Moreover, we fix $\omega=0.5, \beta^{\max }=20, \delta=1$ and $\bar{d}=1$.

The robustness of our qualitative results has been checked by employing Monte Carlo techniques. We have run 100 independent simulations for different values of the initial seed generating the pseudo-random numbers. This exercise has been repeated by changing the parameter $\beta^{\max }$, which represents the maximum value the intensity of choice $\beta$ can reach starting from 5 to 50 with steps of 5 . We have then studied the moments of the distributions of the statistics of interest. Results confirm that our findings are robust.

We start by investigating borrowers and lenders' performances and their effect on the network topology. Then the repercussions of the network architecture on the aggregate

\footnotetext{
${ }^{14}$ The amount of asked loan, $l_{i, t}^{a}$, corresponds to $L_{i, t}^{*}$ in Eq 3 when the borrower $i$ is a firm. However, when $i$ is a bank, $l_{i, t}^{a}=L_{i, t}^{*}-S_{i, t}$.
} 
dynamics are analyzed. Finally, Appendix A shows the model ability in reproducing a remarkable high number of empirically observed regularities, spanning from industrial dynamic to growth type stylized facts.

\subsection{The evolution of the overall financial network: the competition among strategies}

In this section we analyze the mechanism driving the borrowers-lenders' financial relationships in the credit and interbank network. Two are the main forces governing the interaction mechanism. On the one hand, this is driven by the lender ability in signaling, via Eq 14, its credit conditions in terms of liquidity supply and interest rate. On the other hand, the borrower reinforces/reduces the trust in the lender via the intensity of choice parameter, $\beta$. Since the debtor's main concern is not to be rationed, this agent increases its confidence in its creditor when the lender meets the credit requirements. In this fortuitous scenario, the borrower reinforces the $\beta$ parameter and becomes loyal to its lender. Otherwise, in case of rationing, the agent reduces the parameter and acts as a shopper around. Therefore, the overall financial network 15 evolves thanks to the co-movement of lenders which drive the fitness and borrowers which govern the fitness intensity.

We start the analysis by explaining how lenders influence the network evolution. To this end, we identify the bank with the highest number of clients, namely the hub. In Fig. 1 we plot the index of the current hub (black solid line), its percentage of incoming links (i.e its number of clients) (red dotted line) and its fitness (green dashed line), in both the credit and interbank network (top and middle panel, respectively). The figure shows that banks alternate as the hub during the simulation (black solid line). In fact, as the hub acquires too many clients (red dotted line), it may happen that it is not longer able to satisfy its customers due to liquidity shortage phenomena. In this occasion, other banks may become more attractive than the hub itself, as signaled by the fact that the fitness (green dashed line) of the hub becomes, at times, smaller than 1 . As other banks become more appealing, they start to attract more and more clients and eventually one of them becomes the new hub. However, it is worthy of note that hubs, even after their preeminence, often continue to belong to a small group of well connected financial institutions. This finding is shown in Fig, 2, where we display the complete list of all financial institutions that have succeeded as hubs in both the systems, with the respective percentage of clients, from the period 500 onwards. Moreover, by comparing the top and the middle panel of Fig. 1 and the left and right panel of Fig, 2 , we observe that the hubs in the two systems (i.e. credit and interbank market) can coincide during different periods. This phenomenon, as explained below, generates a very strong cen-

\footnotetext{
${ }^{15}$ With the term "financial network" we refer to both our systems (i.e credit and interbank market), which are separately studied in our analysis. Although, in fact, the model reproduces two interconnected networks, the bipartite nature and the star topology of the credit system do not allow us to study the two systems as multilayer or multidimensional network. The reader can find interesting insights on multilayer financial networks in other studies (see, for instance, Montagna and Kok, 2016, Bargigli et al. 2015).
} 

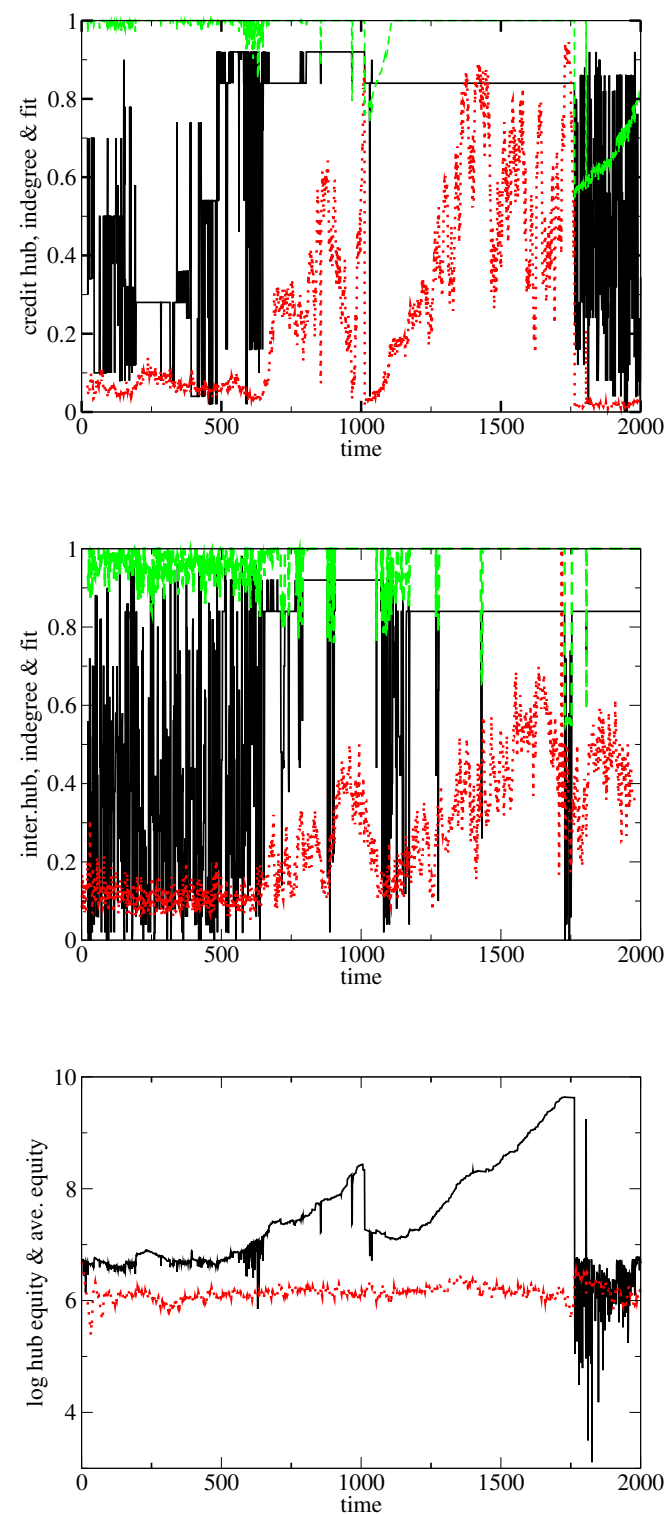

Figure 1: The index of current hub (black solid line), the percentage of incoming link to current hub, i.e number of its borrowers (red dotted line) and fitness of current hub (green dashed line), in the credit and interbank network (top and middle panel, respectively). Equity time series of hub (black line), and rest of lenders (red dotted line) ( bottom panel). Colors are available on the web site version.

tralization of the hub, which can not be any longer able to satisfy its too many clients. It is worth noting that in Eq. 14 two are the key ingredients which reinforce/weaken the hub. Lenders, in fact, compete in term of supply and cost of credit. On the one hand, the 

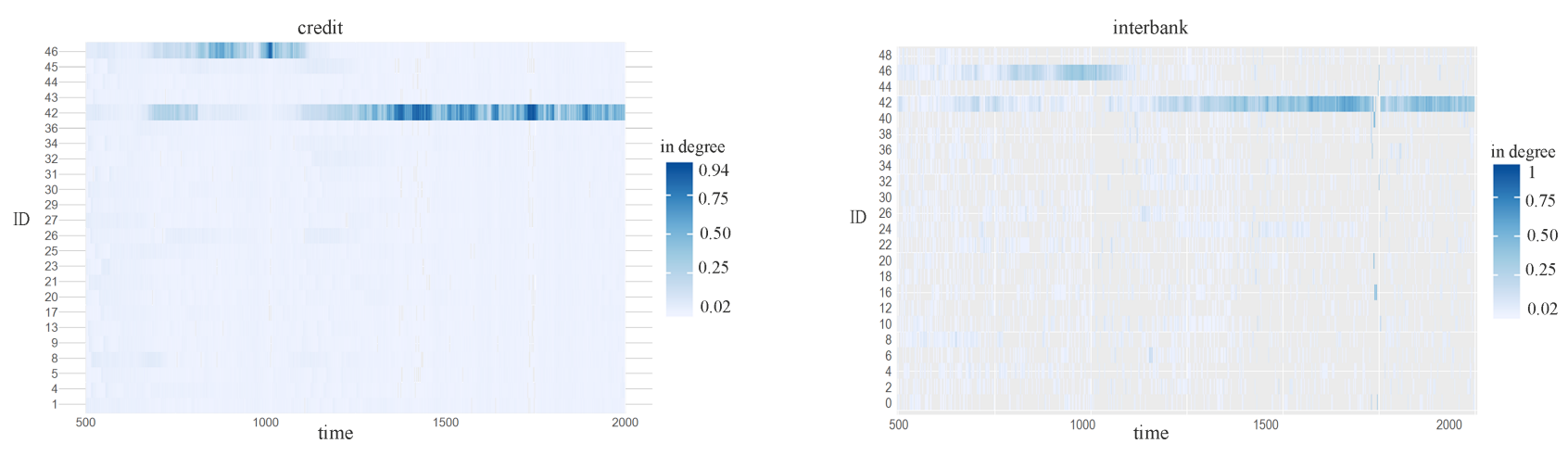

Figure 2: Heatmap of all hubs which have followed from the period 500 onwards, with the respective percentage of incoming links in the credit (left panel) and interbank market (right panel).

bank credit supply and, consequently the fitness, can be compromised by the excessive number of clients the creditor has to meet. In this respect we find a negative correlation ${ }^{16}$ between the hub in-degree in time $t$ and its liquidity in $t+\tau$, with $\tau=1,2,3$ in the credit market (correlation equal to $-0.26,-0.21$ and -0.15 in $\tau=1,2,3$, respectively). Interestingly, this correlation decreases considerably if we look at the second hub, that is the lender with the second highest number of in-degree (correlation equal to -0.11, -0.09 and -0.05 in $\tau=1,2,3$ respectively). The correlation, then, becomes no statistically significant starting from the third hub. Although they have been here omitted, we find very similar results by analyzing the interbank market. This indicates an important phenomenon. When the hub attracts too many borrowers, this can generate congestion effects in financial markets making the lender unable to satisfy its clients' requests.

On the other hand, the credit cost (i.e. the interest rate) is strongly positively affected by the lender leverage (see Eq. 9), which in turn is influenced by the bad debt. When a lender accords a loan to an over-leveraged agent (i.e a borrower with a high probability of bankruptcy) it applies, via the financial accelerator higher interest rate. This, in turn, worsens the financial condition of the borrower itself pushing it towards the bankruptcy state. If one or more borrowers are not able to pay back their loans, even the lenders' equity is affected by bad debts. Therefore, lenders reduce their credit supply and increase the borrowers' rationing. In this way, the profit margin of borrowers decreases and a new round of failures may occur (see Bernanke and Gertler, 1989, Bernanke et al., 1999, Grilli et al., 2014, 2015, Berardi and Tedeschi, 2017). The probability of grafting this negative feedback is clearly more likely for the hub which is unable to closely monitor the financial conditions of all its borrowers. In this respect we find negative correlations between the hub bad debt and its fitness, both in credit and interbank market (correlations equal to -0.24 and -0.22 , respectively). These correlations are no statistically significant just

\footnotetext{
${ }^{16} \mathrm{By}$ construction, in this model there is a positive correlation between the liquidity and the fitness in $t$, and between the fitness and the in-degree in $t$.
} 


\section{Credit market}
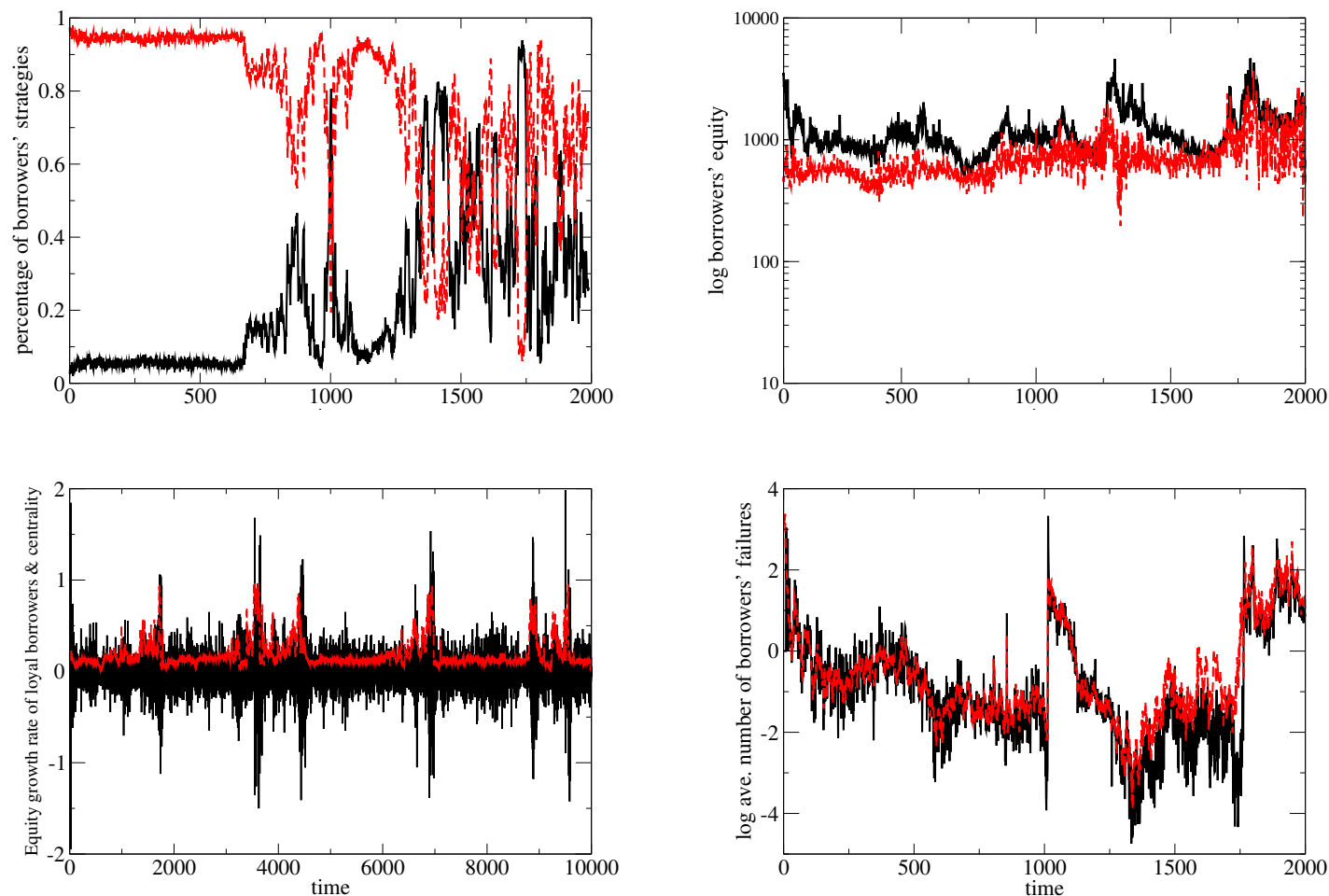

\section{Interbank market}
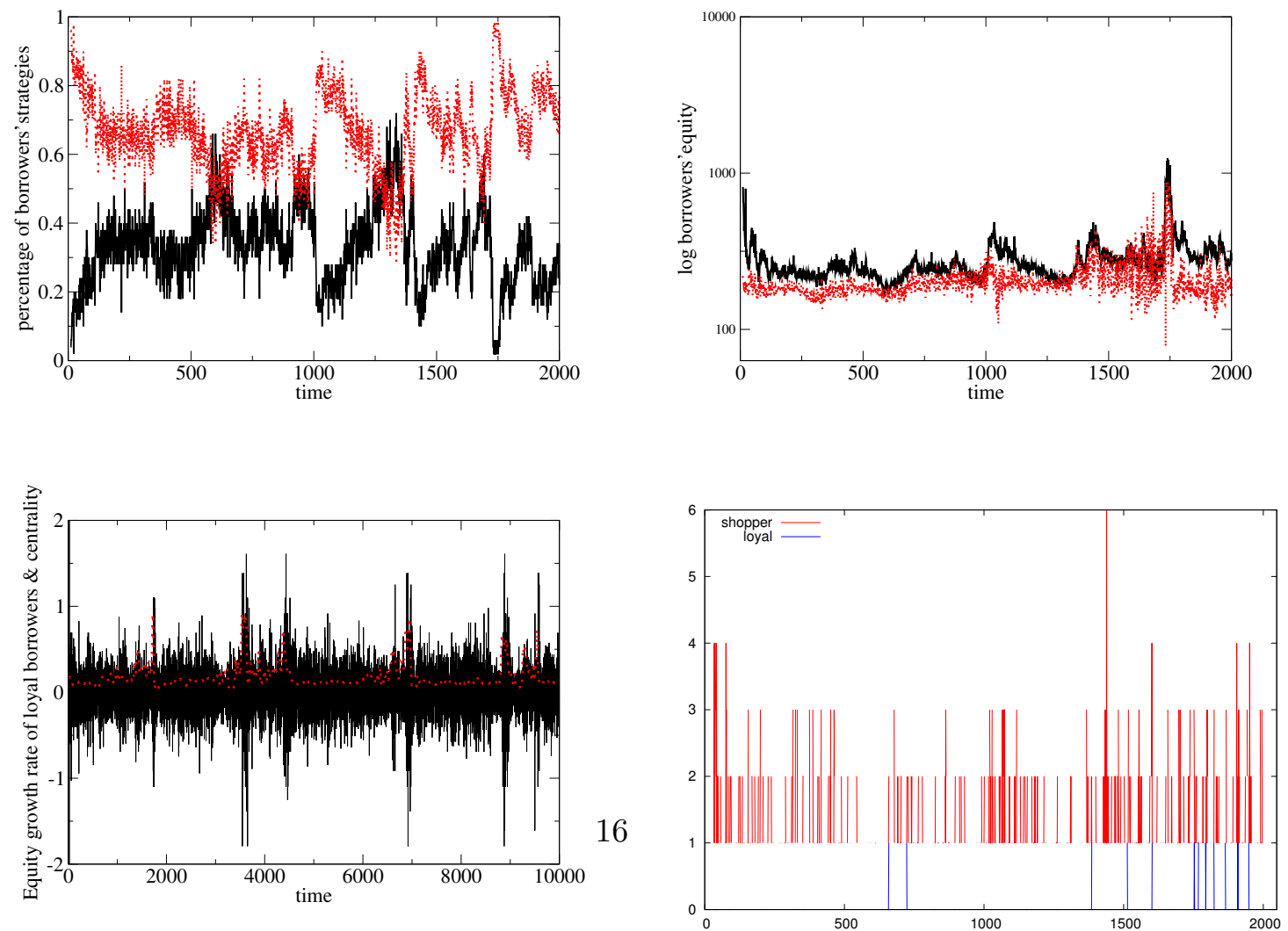

Figure 3: Top left: percentage of loyal and shopper around borrowers. Top right: borrowers' equity. Loyal (shopper around) agents are described by black solid line (red dotted line). Bottom left: equity growth rate of loyal agents (black solid line) and network centrality (red dotted line). Bottom right: average number of loyal and shopper around agents' failures (black solid and red dotted line, respectively). For credit and interbank market, first two top panels and second two bottom panels, respectively. Colors are available on the web site version. 
starting from the second hub. This result once again suggests the negative effect that the excessive number of clients has on the hub.

At this point a question spontaneously arises: why would a bank like to attract clients? The answer is shown in the bottom panel of Fig. 1, where we compare the different performances, in terms of net-worth, of the hub (black line) and the rest of banks (red dotted line). We can observe that the hub, on average, is richer than the rest of the system, and this justifies the emergence of lenders' competition in order to become the hub. Only when a hub does not clearly emerge, we observe a co-movement between net-worths.

We now describe how borrowers influence the network topology. These agents, by choosing their strategy, affect the intensity of choice parameter, $\beta$, which amplifies/reduces the strength of the fitness measure. The first and third left panel of Fig 3 show the evolution of the two strategies in the credit and interbank market, respectively. As the reader can see, the model is able to reproduce switching behavior between loyal and shopping around agents. The effect that behavioral switching mechanisms, or coordination of traders' strategies, have in generating persistence of price volatility is well documented in economic literature (see, for instance, Lux and Marchesi, 2000: Chiarella et al., 2009; Gaunersdorfer et al., 2008; Brock and Hommes, 1997; Tedeschi et al., 2009, 2012a). Specifically, agent-based literature focuses on the impact that these mechanisms have on financial markets (see, Hommes, 2006, for a survey of the relevant literature). Moreover, in recent years, also macroeconomic literature has started to analyze the impact of this mechanism on real markets and its effect in generating business fluctuations (see, for instance, De Grauwe and Macchiarelli, 2015).

The rest of this session investigates the performance of these two strategies in both systems and their repercussions on financial relationships.

In the first and third right panel of Fig. 3 we compare the different performances, in terms of equity, of loyal (black solid line) and shopping around borrowers (red dotted line) in the credit and the interbank market, respectively. The figures show a tight competition between the two strategies with a slight predominance of the loyal one. Specifically, the average net-worth of loyal borrowers in the credit market (shoppers around) over time and simulation is equal to $1602.3 \mathbf{( 7 8 6 . 0 )}$ ) with standard deviation $593.6 \mathbf{( 3 3 1 . 8 )}$. Similar performances between the two strategies are found in the financial market, where the average net-worth of loyal borrowers (shoppers around) over time and simulation is equal to $1567.8 \mathbf{( 7 6 1 . 1 7 )}$ with standard deviation $777.3 \mathbf{( 3 0 3 . 4 )}$. Whilst the highest value of the average equity of loyal borrowers could suggest better performance of these agents, the highest variance weakens this result. On the one hand, simulated results explain the high value of the average net-worth of loyal agents with the low rationing affecting this population ${ }^{17}$. On the other hand, the high variance affecting the loyal agents' equity can be explained by the gridlock effects that this strategy can engage. In

\footnotetext{
${ }^{17}$ Specifically, in the credit market, the average percentage of loyal agents' rationing (shoppers around) over time and simulation is equal to $6.2 \% \mathbf{( 1 0 . 3 \% )}$ with standard deviation $1.9(\mathbf{0 . 6})$. In the interbank market, these percentages are equal to $3.1 \%$ (st. dev 1.01) and $4.3 \%$ (st. dev 0.91) for the loyal and shopping-around agents, respectively.
} 


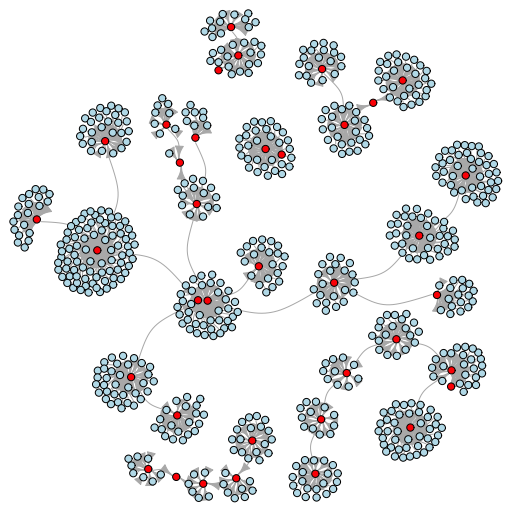

Credit model

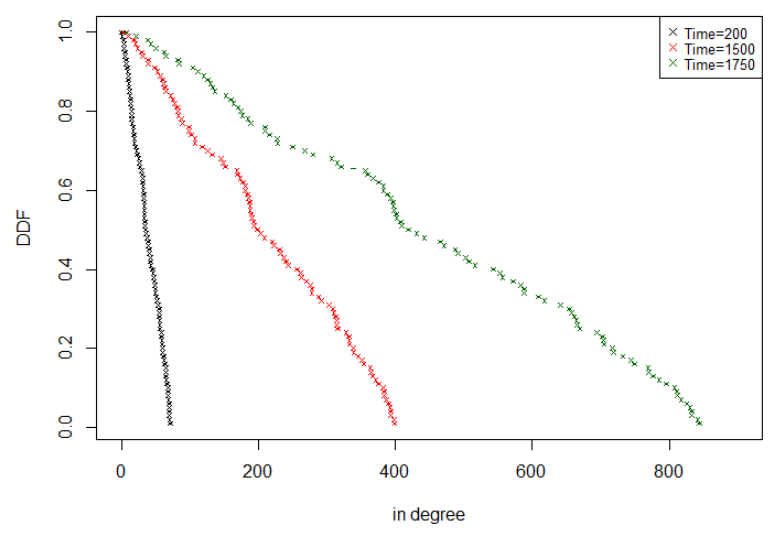

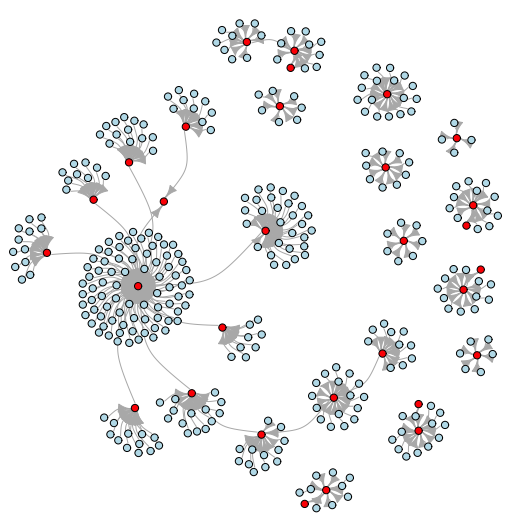

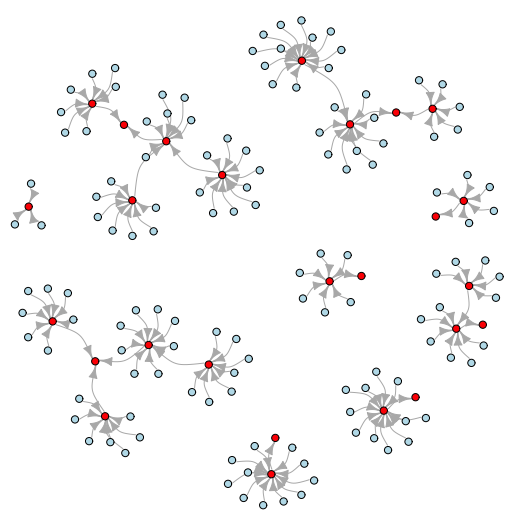

Interbank model

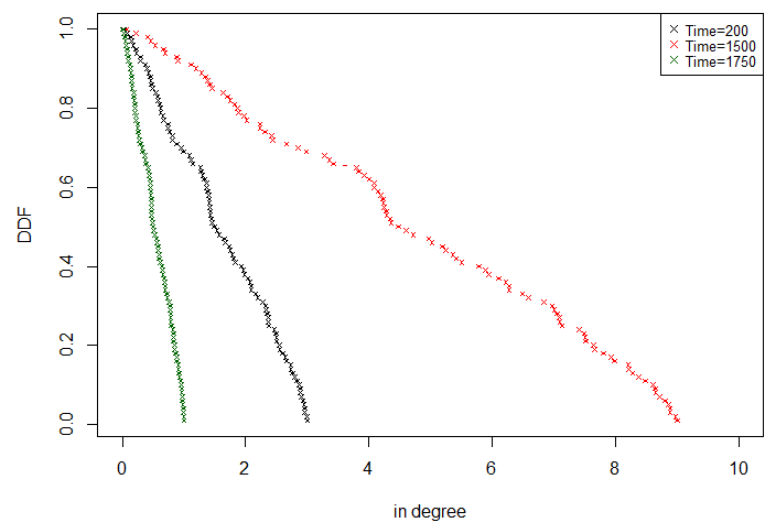

Figure 4: Top panel: network configuration at $t=200,1500$ and 1750 (left, center and right panel, respectively). Red nodes represent banks and black firms. Bottom panel: in-degree distribution for the same time periods in the credit and interbank system, left and right panel respectively. Colors are available on the web site version.

this regard, it is worthy of note that the two strategies only diverge in the counterpart search mechanism: loyal borrowers try not to be rationalized by exploiting their fiduciary relationships, while shoppers-around look around to find the best credit conditions. The first strategy tends to address borrowers to few big creditors, thus centralizing the network, the second one, instead, disperses the debtors and decentralizes the financial market. Clearly, an excessive concentration of debtors towards few creditors can cause credit-crunch phenomena. In this respect, on the one side, we find positive correlations, equal to 0.31 and 0.29 , between the network centrality and the loyal agents' rationing in both credit and interbank system respectively ( this correlation is statistically not significant for shopping-around borrowers); on the other side, we detect volatility clustering in the growth rate of loyal-agents' equity associated with periods of high network 
centrality ${ }^{18}$ (see the second and fourth left panel Fig 3 ). This result emphasizes a key point: loyal strategy centralizes the networks, and this generates high volatility in the equity of loyal agents due to the possible emergence of rationing phenomena.

The second and fourth right panel of Fig 3 show another important indicator of the performances of the two strategies, namely the number of failures affecting loyal (black solid line) and shopping around (red dotted line) borrowers in both the systems. Even in this case, we notice that loyal borrowers slightly overperform shoppers-around in the credit system (see the second right panel). Specifically, the average number of bankruptcy, over time and simulation, for loyal agents (shoppers around) is equal to $0.98 \mathbf{( 1 . 2 0 )}$ with standard deviation $0.21(\mathbf{0 . 0 8})$. Once again, in this market, the best performances of loyal borrowers in terms of average values are weakened by the too high variance emerging during episodes of network congestion generated by strengthening the loyal strategy itself. However, by analyzing the interbank system (see the fourth right panel), the performances of the loyal banks in term of their survival capacity are clearly above those of the shopping-around financial institutions. This result depends on the low number of bankruptcies in the interbank market. Given that in the model the attack is generated by the firms' bankruptcy in the credit market, the figure shows that the main source of banks' suffering ends up in the credit market without necessarily propagating into the interbank system. However, it is worth noting that in some periods, as for instance in $t=1476$, the model generates bankruptcy cascades which correspond to the simultaneous bankruptcy of many financial institutions. By observing the second and fourth left panel of Fig.3, we can deduce the reason: in this time step the credit and interbank centrality reach their maximum value, and this generates bankruptcy cascades.

As mentioned at the beginning of this session, it is the co-movement of creditors and debtors to determine the evolution of the overall financial network. In the top panel of Fig. 4, we plot one shot of the configuration of the endogenous network at $t=200,1500$ and 1750. The graphs show that the network changes its topology over time and goes through phases of higher and lower centralization. Specifically, in the left panel of Fig. 4, we notice a faint centralization of the system with several banks attracting customers. As time goes by, the network becomes more and more centralized with a small number of attractive lenders, as displayed in the central panel of the same figure. Then, we observe a subsequent decentralization of the network, where financial institutions are able to attract just very few borrowers, as illustrated in the right panel of the figure19. The evolution in the network topology over time is also confirmed by the different shapes of the in-degree distributions as shown in the bottom panel of the same figure. As the reader can observe, although the two systems are often synchronized, as in the periods 200 and 1500, there are times where the two topologies do not match as, for instance, in period 1750. In this time step, we can observe that, while the credit system is still highly centralized and its network topology is scale-free, the interbank

\footnotetext{
${ }^{18}$ As the reader can see the second and fourth left panel of Fig 3 display a time series of 10000 periods. This allows us to highlight how this dynamic is persistent during long time horizons.

${ }^{19}$ The several phases the financial network goes through correspond to the hubs' alternation as shown in Fig. 1
} 
market is not anymore centralized and its topology is random. The dynamics of the

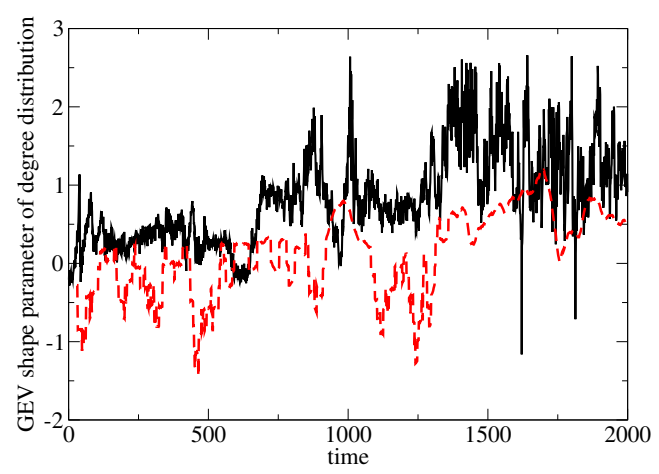

Figure 5: time evolution of the shape parameter $\xi$ of GEV distribution estimeted on the in-degree distribution tails over time in the credit (black solid line) and interbank market (red dotted line).

network topology is better quantified in Fig, 5 , where we estimate ${ }^{20}$, on the upper tail of the banks' in-degree distribution (from the 70th percentile onward) for the credit and interbank system, the evolution of the shape parameter $\xi$ of the generalized extreme value (GEV) distribution. The figure shows that, over the time, financial linkages selforganize themselves into very different network architectures. In fact, values of $\xi \leq-0.5$ represent a very rapid tail decay approaching a Poisson distribution. While values of $\xi \geq 0$ reproduce fatter tails ranging from the exponential to the power law distribution. This proves the ability of the model in reproducing an important stylized fact of financial networks, that is banks' degree distributions often exhibit power law dependencies (see, for instance, Boss et al., 2004, Iori et al., 2008). Finally, the two time series shown in Fig. 5 provide another interesting information: the strong co-movement between the two networks' topologies, also confirmed by their positive and statistically significant correlation equal to 0.66 .

\subsection{The impact of the network architecture on the macroeconomic performances}

We now investigate the consequences that the evolution of the financial network topology has on business fluctuations. The validity of the results presented in this section derives from the model ability to reproduce many stylized facts as shown in Appendix

\footnotetext{
${ }^{20}$ In order to verify the robustness of our estimation we have applied the following two-steps methodology: 1) we have randomly extracted a subsample of 500 non-zero $\xi$ parameter values. To this subsample we have applied a log ratio test testing whether our $\xi$ were significantly different from zero. The test has confirmed that the $97 \%$ of our extractions were statistically significant. 2) Having successfully proven the log ratio test for the value of $\xi$ parameters, we have then employed a MLM test as in Clauset et al. (2009) to verify whether the shape distributions are better fitted by a Poisson, an exponential or a Power law.
} 
A. Specifically, having successfully proved our model for output validation, we can test its capability in describing the impact of the financial network architecture on business cycles.

First of all, the model robustly generates endogenous self-sustained growth patterns characterized by the presence of persistent fluctuations, as shown in Fig.6 (left panel). The aggregate output, indeed, shows an alternation of aggregate booms and recessions as a non-linear combination of idiosyncratic shocks affecting individual decision-making processes. Moreover, aggregate fluctuations, measured by output growth rates (center
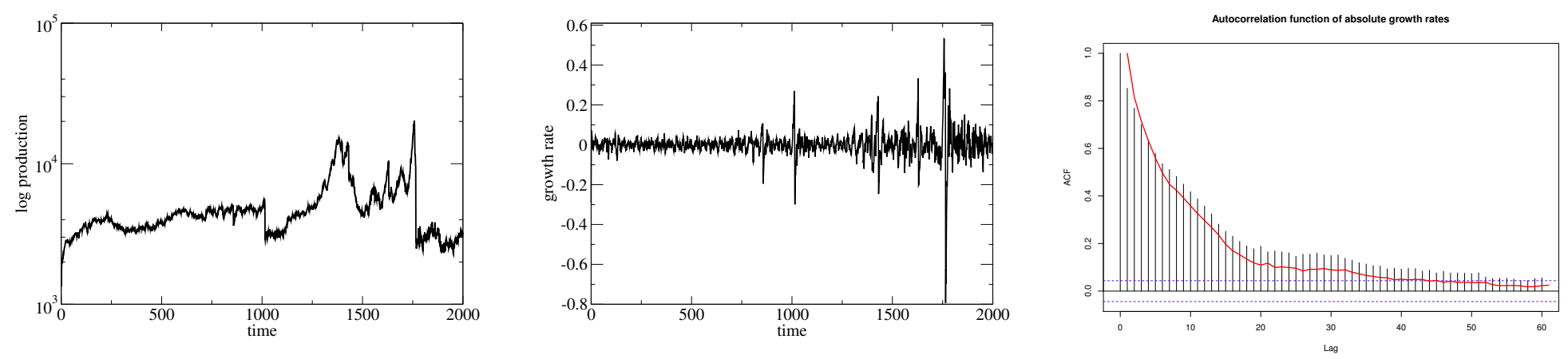

Figure 6: Evolution of the aggregate output (left panel) and growth rates of the aggregate output (center panel), as a function of time. Autocorrelation of the absolute growth rates and the power law best fit- red line, (right panel). Colors are available on the web site version.

panel of Fig. 6), are path dependent (i.e., nominal shocks have real and permanent effects), and characterized by cluster volatility (see, for instance, Stanca and Gallegati, 1999: Tedeschi et al., 2009, 2012b; Grilli et al., 2014). A quantitative manifestation of this fact is that, absolute growth rates display a positive, significant and slowly decaying autocorrelation function which is well fitted by a power law (see right panel of Fig. 6). In addition to fluctuations resembling business cycles, the simulated time path of aggregate activity is characterized by broken-trend behavior as shown in the left panel of Fig 6 where two important episodes occur: the first one at $t \approx 1000$ and the second one at $t \approx 1750$.

Now, therefore, in consideration of the promises herein above made, we investigate the key elements able to generate expansions and depressions in our model. Specifically, our analysis focuses on two ingredients which have a clear impact on business cycles, namely the gridlock effect caused by an excessive centralization of the two financial networks and the financial fragility of agents. About the first point, it is worth remembering that the networks' evolution is driven by i) the lender fitness and ii) the borrower intensity of choice. It is the mutual reinforcement between these two elements to make the networks centralized to a few hubs attracting many loyal clients. In order to measure the impact of lender fitness and borrower intensity of choice on the overall financial network, we build an indicator detecting the co-movement between the two. Specifically, the indicator uses the combination of the two degree centralities as a measure of the lender performance 
and the total number of loyal borrowers in both systems as a proxy of the intensity of choice parameter. The co-movement between the two, then, is simply the positive value of the product between the growth rates of the two variables. Left panel of Fig 7 shows
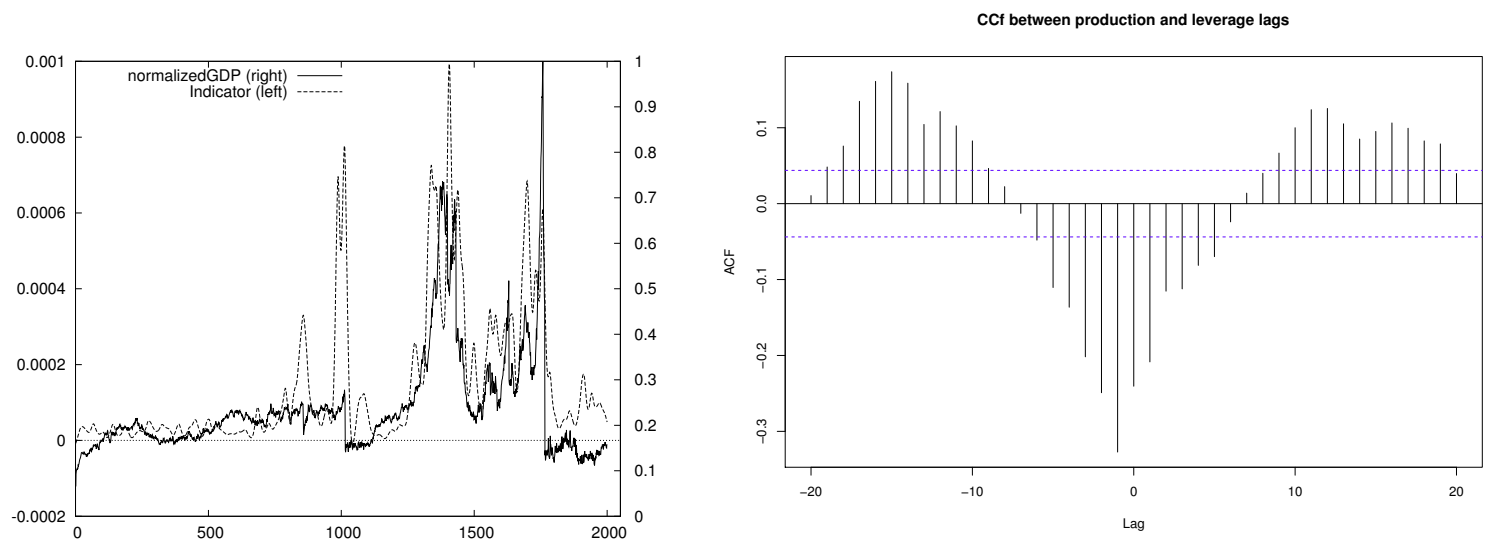

Figure 7: Left panel: time series of the normalized aggregate output (black solid line) and the indicator (black dotted line). Right panel: Average correlation between aggregate output $Y_{t}$ and lagged leverage, at a $1 \%$ confidence level.

the evolution of the normalized aggregate output (black solid line) and the indicator (black dotted line). The figure confirms an important characteristic of the model: when the both the networks are highly centralized and debtors establish strong fiduciary relationships (i.e. for high values of the indicator), GDP is characterized by the onset of bubbles. Moreover, when the indicator reaches its maximum values, the production drastically collapses, as confirmed by the two episodes of broken-trend behavior. Last but not least, the correlation between the indicator and the credit rationing proves that a too centralized network, where few hubs trying to meet many loyal clients, generates congestion phenomena and credit-crunch. In this regard, Table 1 shows the correlations between the aggregate credit rationing and the lagged time series of the indicator $I c_{t-\tau}$. The correlation shows a first positive effect of the centralization on credit supply, as shown by the negative values at $\tau=2$ and 3 . The effect, then, becomes detrimental when the centralization becomes too high, as shown by the positive values at $\tau=1$ and 0 .

\begin{tabular}{ccccc}
\hline Correlation & $\operatorname{Lag} \tau=0$ & $\operatorname{Lag} \tau=1$ & $\operatorname{Lag} \tau=2$ & Lag $\tau=3$ \\
$R_{t}-I c_{t-\tau}$ & 0.1689 & 0.0019 & -0.1509 & -0.2092 \\
\hline
\end{tabular}

Table 1: Correlations between the aggregate rationing $R_{t}$ and the indicator, $I c_{t-\tau}$, with $\tau=0 ; 1 ; 2 ; 3 ;$ at a $1 \%$ confidence level.

About the second point, namely the financial fragility of agents, the model reproduces the Minskyan hypothesis of the nonlinear effect of indebtedness on economic cycle. In fact, we observe that over periods of prolonged prosperity and economic growth financial 
institutions grant more loans without considering the overall financial fragility. However, it can happen that banks underestimate their credit risk, making the economic system more vulnerable when default materializes. This ambiguous effect of the leverage, first positive and then negative, on business fluctuation, is clearly shown in the right panel of Fig.7, where the correlation wave between the production and agents' leverage first increases from $\tau=-20$ up to $\tau=-10$, then decreases from $\tau=-6$ up to $\tau=5$, and finally, returns to increase from $\tau=9$.

In accordance with many other studies (see, Battiston et al., 2007, 2012b a; Berardi and Tedeschi, 2017; Caccioli et al., 2012, Iori et al., 2006), our results show that a combination of forces is needed to generate economic fluctuations. On the one hand, the network topology is a key ingredient to cause these phenomena. In fact, the position of agents in the financial network, the degree distribution and the centrality of the system, can provoke gridlock effects and credit crunch episodes. On the other hand, agents' financial fragility seems to be a leading force in generating cycles. Indeed, when variations in the level of financial robustness of agents tend to persist in time or to get amplified, credit linkages among financially fragile firms/banks represent a propagation channel for contagion and a source of systemic risk able to trigger fluctuations and broken-trend behaviors.

\section{Robustness analysis}

To better quantify these observations we apply a Fixed-Effects Panel Regression model on the simulated database and show the impact of agents' characteristics and financialnetwork architecture on the credit supply (Model (a), hereinafter) and on the aggregate production (Model (b), hereinafter). Moreover, we also test the robustness of Model (a) using a different data sample just composed by loyal borrowers in both the credit and interbank system. Given this sample restriction, then, this econometric model is a Pooled OLS.

The general specification of the models is $Y_{t}=\alpha+c+\mathbf{X}_{\mathbf{t}} \beta+\gamma d_{t}+\epsilon_{t}$, where $Y_{t}$ denotes a $N \times 1$ vector consisting of observations of the dependent variable for every borrower $i=1, \ldots, b$ at a particular point in time $t=1, \ldots, T . \mathbf{X}_{\mathbf{t}}$ is a $N \times K$ matrix of exogenous economic and network covariates with associated (own) $\beta$ parameters. $\gamma$ is the time dummy variable and $c=\left(c_{1}, \ldots, c_{N}\right)$ is a vector with borrower fixed effects to control for all individual-specific time invariant variables whose omission could bias the estimates. Finally, $\epsilon_{t}$ is a vector of i.i.d disturbances whose elements have zero mean and finite variance $\sigma^{2}$.

Before starting the detailed analysis on the two econometric modes, some general remarks are essential: i) the database used in the analysis is composed of borrowers $b$ and lenders $e$. Depending on the market we are considering (i.e. credit or interbank system), these two groups of agents are distinct subjects. More in detail, in the Model (a) with fixed-effects, in the analysis of the credit market (interbank system) borrowers are just firms (banks). In the OLS Model (a), in the study of the credit market (the interbank market), our borrowers are only loyal firms (loyal banks). Finally, in the Model (b) with fixed-effects we just analyze the credit market, and consequently, our borrowers are only firms and lenders just banks operating in the credit system. ii) in both the 
econometric models, we consider logarithmic differences of all variables (dependent and independent); iii) in both analyzes, the choice of a fixed-effects model is supported by the Hausman test, which is reported at the end of each tables.

Let us now specify Model (a). Here, the dependent variable is the borrower granted loan, $L_{b}^{g}$. The independent variables are the borrower and lender leverages $\lambda$, the borrower intensity of choice $\beta_{b}$, the average degree of neighboring borrower $k n n_{b}$, the lender degree $\operatorname{deg}_{e}$ and the lender centrality score $C_{e}$. Furthermore, we include two dummy variables: the first one catches the role of loyalty, is_loyal, the second one accounts for economic recessions, crisis. Following Catullo et al. (2017), this second dummy identifies periods where the production collapse ${ }^{21}$ of more than $5 \%$.

In Tab 2 we show Model a) regression results. As the reader can notice the model with fixed-effects reinforces the observations previously made. Specifically, an over-centralized network generates credit squeeze, as confirmed by the coefficients' negative value of the intensity of choice, (i.e. $\beta_{b} \approx-0.15(-0.11)$ in the credit (interbank) system), the eigenvector centrality (i.e. $C_{e} \approx-0.26(-0.07)$ in the credit (interbank) market) and the degree (i.e. $\operatorname{deg}_{e} \approx-2.02(-0.05)$ in the credit (interbank) market). Also agents' financial fragility plays a crucial role in the credit delivery. In fact we observe that "leveraged" lenders decrease their credit supply, as confirmed by the negative value in the coefficient $\lambda_{e}$, which is approximately equal to $-0.03(-0.01)$ in the credit (interbank) system. The negative relationship between granted loan and lender leverage is a model assumption. In fact, following the Basel III regulatory framework, Eq.77 imposes an upper bound to banks' total exposure, which clearly triggers this negative relation. More unexpected is, instead, the positive relationship between granted loan and borrower leverage in the credit (interbank) market (i.e. $\lambda_{b} \approx+2.2(+16)$ ). With regard to this point, empirical literature (see, for instance, Mayer, 1988, Berger and Udell, 1995) observes that borrowers with a long indebtedness tradition (i.e. leveraged borrowers) have higher probability of receiving new loans. Overall, it is the continuous leverage-loan back and forth phenomenon to generate nonlinear relationships between aggregate output and leverage, as shown in the right panel of Fig.7.

Finally, the econometric analysis reinforces another important feature of the model, that is loyal agents have easier access to credit than shoppers around. This is confirmed by the high positive value of the dummy variable is_loyal $\approx+0.4(+0.02)$ in the credit (interbank) system.

As a whole, however, the model highlights the ambiguous relationship between credit and loyalty. On the one hand, our results enrich the literature on "relationship lending" (see, for instance, Berger and Udell, 1995; Petersen and Rajan, 1995; Boot, 2000; Cao and Shi, 2001), proving that financial institutions, thanks to long-term loyalty relationships, acquire private information on their counterparts and these facilitate credit flow. On the other hand, our analysis highlights the disadvantages of the loyal strategy. This behavior, indeed, can cause credit crunch phenomena, that materialize during periods of an excessive centralization of the credit network (see, for instance, Butler J. et al.,

\footnotetext{
${ }^{21}$ A sensitivity analysis on the dummy variable "crisis" has been conducted. Econometric results remain robust and consistent with Tab 2 by considering production drops of more than $3 \%, 5 \%$ and $7 \%$.
} 
Model a) Fixed-effects and OLS in credit and interbank market Dependent variable: $\Delta \log \left(L^{\mathrm{g}}{ }_{b}\right)$

\begin{tabular}{|c|c|c|c|c|}
\hline \multirow[b]{2}{*}{ Coefficient } & \multicolumn{2}{|c|}{ FE model } & \multicolumn{2}{|c|}{ OLS model } \\
\hline & Credit & Interbank & Credit & Interbank \\
\hline \multirow[t]{2}{*}{ const } & $-0.006^{*}$ & $-0.120 * * *$ & $0.322^{* * *}$ & $-0.147^{* * *}$ \\
\hline & $(0.003)$ & $(0.012)$ & $(0.014)$ & $(0.018)$ \\
\hline \multirow[t]{2}{*}{ is_loyal } & $0.483^{* * *}$ & $0.024^{*}$ & - & - \\
\hline & $(0.048)$ & $(0.017)$ & $(-)$ & $(-)$ \\
\hline \multirow[t]{2}{*}{ crisis } & $-0.237^{* * *}$ & -0.010 & $-0.517^{* * *}$ & $-0.012^{*}$ \\
\hline & $(0.020)$ & $(0.040)$ & $(0.037)$ & $(0.008)$ \\
\hline \multirow[t]{2}{*}{$\Delta \log \left(k n n_{b}\right)$} & -0.000 & -0.018 & 0.001 & -0.029 \\
\hline & $(0.000)$ & $(0.011)$ & $(0.001)$ & $(0.024)$ \\
\hline \multirow[t]{2}{*}{$\Delta \log \left(\lambda_{b}\right)$} & $2.209^{* * *}$ & $16.48^{* * *}$ & $3.006^{* * *}$ & $16.255^{* * *}$ \\
\hline & $(0.036)$ & $(0.379)$ & $(0.042)$ & $(0.369)$ \\
\hline \multirow{2}{*}{$\Delta \log \left(\beta_{b}\right)$} & $-0.158^{* * *}$ & $-0.110^{* *}$ & $-0.861^{* * *}$ & $-0.308^{* * *}$ \\
\hline & $(0.020)$ & $(0.027)$ & $(0.089)$ & $(0.098)$ \\
\hline \multirow[t]{2}{*}{$\Delta \log \left(C_{e}\right)$} & $-0.261^{* * *}$ & $-0.067^{* * *}$ & $-0.470^{* * *}$ & $-0.077^{* * *}$ \\
\hline & $(0.009)$ & $(0.015)$ & $(0.025)$ & $(0.018)$ \\
\hline \multirow[t]{2}{*}{$\Delta \log \left(\operatorname{deg}_{e}\right)$} & $-2.023^{* * *}$ & $-0.055^{* * *}$ & $-1.782^{* * *}$ & $-0.070^{* * *}$ \\
\hline & $(0.043)$ & $(0.008)$ & $(0.043)$ & $(0.011)$ \\
\hline \multirow[t]{2}{*}{$\Delta \log \left(\lambda_{e}\right)$} & $-0.030^{* * *}$ & $-0.015^{*}$ & -0.001 & -0.019 \\
\hline & $(0.005)$ & $(0.001)$ & $(0.017)$ & $(0.021)$ \\
\hline Sum squared resid & 4129572 & 289978.6 & 520650.5 & 248959.7 \\
\hline$R^{2}$ & 0.574 & 0.274 & 0.556 & 0.252 \\
\hline Within $R^{2}$ & 0.573 & $0.274 \mathbf{I}$ & $\operatorname{Adj} R^{2} 0.555$ & 0.252 \\
\hline \multirow[t]{2}{*}{ Hausman test } & $\mathrm{H}=123.966$ & $\mathrm{H}=17.148$ & - & - \\
\hline & $\mathrm{p}$-value $=0.000$ & $\mathrm{p}$-value $=0.02$ & - & - \\
\hline Durbin-Watson & 2.771 & 2.758 & - & - \\
\hline Akaike criterion & 2644884 & 211773.0 & 255778.6 & 139974.6 \\
\hline
\end{tabular}

Table 2: Model (a): FE in credit (interbank) market using 543065 (45030) observations. Included 1000 (50) cross-sectional units. Time-series length: minimum 376 (536), maximum 1007 (1415). OLS in credit (interbank) market, using observations 1-113251 $(1-30782) \mathrm{n}=49216(\mathrm{n}=27830)$.

2016; Hémous D. and Olsen M., 2017).

The impact of the loyal strategy on the credit allocation is better investigate in the OLS model presented in the last two columns of Tab2, where we run the same regression as in Model (a), but considering as sample just the subset of loyal borrowers in both system. The results of the OLS model reproduce the same dynamics of the above-described 
model but with a higher magnitude of many of the estimated coefficients. In particular, it is worth noting that, when the sample is just composed by loyal borrowers, the value of coefficients describing the network centrality (i.e. $\beta, C$ and $d e g$ ) are magnified with respect to the complete sample. Once more, this result highlights the impact of the loyal borrowers on centralizing the credit network and the resulting effect in generating credit crunch phenomena.

Let us now describe Model (b), where the macroeconomic consequences of agents' characteristics and credit network architecture are investigated. Here, the dependent variable is the firms' production $Y_{b}$ which, in our simple framework, reflects the aggregate output. Control variables are: i) the firm rationing $R_{b}$ and granted loan $L_{b}^{g}$, on the real side of the economy, ii) the borrower intensity of choice $\beta_{b}$, its square value $\beta_{b}^{2}$, the lender degree $\operatorname{deg}_{e}$ and the lender centrality score $C_{e}$, on the financial side of the credit market. Furthermore, we include a dummy variable accounting for the role of loyalty, is_loyal. Tab. 3 shows Model b) regression results. Not surprisingly, the two real variables, namely rationing and granted loan, have the expected impact on the production (i.e. they negatively and positively affect the macroeconomic outcome, respectively).

The impact of the network variables on the macroeconomic performances well aligns with the results described above. Specifically, our findings confirm the negative impact of the network centrality on the aggregate output, as demonstrated by the negative value of the lender centrality and lender degree coefficients. Regarding the effect of the intensity of choice parameter, our estimates support the presence of a nonlinear relationship between loyalty and production. Indeed, a moderate loyalty level allows firms to grow, as demonstrated by the positive value of $\beta \approx 0.04$. However, an excessive level of loyalty reduces production, as confirmed by the negative value of $\beta^{2} \approx-0.02$. The U-shaped relation between loyalty and macroeconomic performances can be explained by the emergence of bottleneck phenomena in the credit allocation due to the excessive network centralization.

Finally, the econometric analysis reveals a non-statistical significance of the dummy, is_loyal, on the production. As already highlighted in session 3.1, where the performance between the two strategies are analyzed, the weak supremacy of loyal agents in terms of average wealth is weakened by the strong variance associated with this strategy. The fact that the loyal strategy does not have a statistically significant impact on production further strengthens this result.

\section{Concluding remarks}

In this paper we have analyzed in a multi-market framework, composed by goods, credit and interbank system, the impact of agents' behavior and network topology on business fluctuations. By implementing an endogenous mechanism of credit-links formation, which evolves via the co-movement of borrowers-lenders' specific variables, we have been able to reproduce a dynamic financial system where agents can switch strategies. Specifically, on the one hand, lenders try to attract clients by offering liquidity at subsidized 
Model b: Fixed-effects, using 394008 observations

Included 1000 cross-sectional units

Time-series length: minimum 262, maximum 715

Dependent variable: $\Delta \log \left(Y_{b}\right)$

Robust (HAC) standard errors

\begin{tabular}{lclrl} 
& Coefficient & \multicolumn{1}{c}{ Std. Error } & $t$-ratio & p-value \\
const & 0.0359692 & 0.000300487 & 119.7030 & 0.0000 \\
$\Delta \log \left(R_{b}\right)$ & -0.0218479 & 0.000446293 & -48.9543 & 0.0000 \\
$\Delta \log \left(L^{\mathrm{g}} b_{b}\right)$ & 0.134123 & 0.00269082 & 49.8446 & 0.0000 \\
$\Delta \log \left(C_{e}\right)$ & -0.0349404 & 0.000951759 & -36.7114 & 0.0000 \\
$\Delta \log \left(d_{e} g_{e}\right)$ & -0.0831739 & 0.00361431 & -23.0124 & 0.0000 \\
$\Delta \log \left(\beta_{b_{F}}\right)$ & 0.0431854 & 0.00291757 & 14.8018 & 0.0000 \\
$\Delta \log \left(\beta_{b_{F}}\right)^{2}$ & -0.0215606 & 0.00291583 & -7.3943 & 0.0000 \\
is $\operatorname{loyal}$ & 0.000363729 & 0.00146713 & 0.2479 & 0.8042 \\
Mean dependent var & 0.034404 & S.D. dependent var & 0.518889 \\
Sum squared resid & 43972.49 & S.E. of regression & 0.334498 \\
LSDV $R^{2}$ & 0.585496 & Within $R^{2}$ & 0.584473 \\
$F(1006,393001)$ & 551.8123 & P-value $(F)$ & 0.000000 \\
Log-likelihood & -127081.4 & Akaike criterion & 256176.8 \\
Schwarz criterion & 267137.1 & Hannan-Quinn & 259310.6 \\
$\hat{\rho}$ & -0.384968 & Durbin-Watson & 2.573795
\end{tabular}

Joint test on named regressors -

Test statistic: $F(7,393001)=78969.6$

with p-value $=P(F(7,393001)>78969.6)=0$

Test for differing group intercepts -

Null hypothesis: The groups have a common intercept

Test statistic: $F(999,393001)=1.67034$

with p-value $=P(F(999,393001)>1.67034)=2.63515 \mathrm{e}-36$

Hausman test statistic -

$\mathrm{H}=766.39$

with p-value $=P\left(\chi^{2}(7)>766.39\right)=3.31395 \mathrm{e}-161$

Table 3: Model (b)

rates; on the other hand, borrowers establish loyal relationships based on the previously granted loan. The co-movement between these two forces generates an evolutionary system where the lenders' competition to attract clients and the borrowers' switching between the loyal and shopping-around strategy reproduce different networks configurations ranging from the random to the scale-free one. This simple mechanism of dynamic 
interaction, therefore, has allowed us to analyze both the individual performances of lenders and borrowers, and the macroeconomic consequences of their interconnection. Our findings have detected a trade-off between micro and macro performances. At the individual levels, indeed, our analysis has shown that, on the one side, landers have an incentive to act as hubs and, on the other side, borrowers have a benefit to behave as loyal clients. At the aggregate level, however, the coexistence of these two attitudes generates gridlock effects in the network and the emergence of credit crunch phenomena. More in detail, our results have suggested that the appearance of a large lending financial institution able to attract many loyal customers tends to centralize too much the financial system, and this causes adverse effects on the credit supply and the aggregate outcome. Overall, we have detected that a possible reason for cycles to appear is the clash between the two system attractors, that is the tension between shopping-around and loyal agents. Indeed, the former work as a thermostat of the system by realigning macroeconomic time series to its "fundamental" level, while the latter generate macroeconomic instability and financial bubbles.

Obviously, these findings are specific to the model, but they offer an interesting further insight into the nature of economic fluctuations and suggest some economic policy countermeasures. First, our analysis shows that the regulator should pay more attention to the architecture of the credit market and try to avoid network concentration phenomena. Second, the police maker should redirect the credit system to small local banks able to meet the financial needs of a limited number of loyal clients. This would allow i) to avoid gridlock effects and credit-crunch phenomena ii) to closely monitor the financial conditions of borrowers iii) to limit bailout policies applied to systemically important financial institutions (i.e. hubs in our context).

\section{Acknowledgements}

Gabriele Tedeschi is grateful for the financial support by the Universitat Jaume I (grant UJI-B2018-77) and the Spanish Ministerio de Ciencia, Innovacion y Universidades (grant $R T I 2018-096927-B-I 00)$. 
value over time and simulations of the former is 0.57 (st. dev 0.28 ), while of the later is 0.00 (st. dev 0.03).
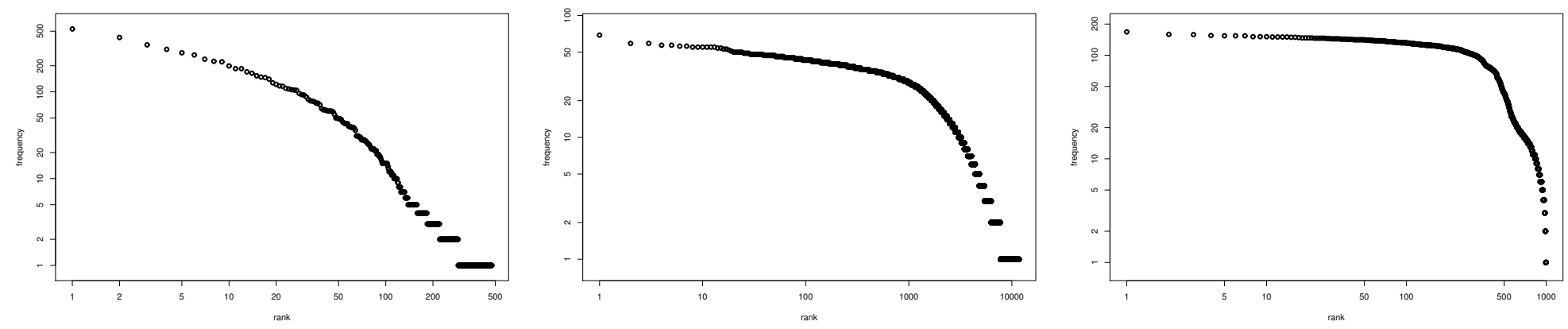

Figure 9: Zipf plot of amount of loans, bad debts and bankruptcies; left, center and right panel respectively.
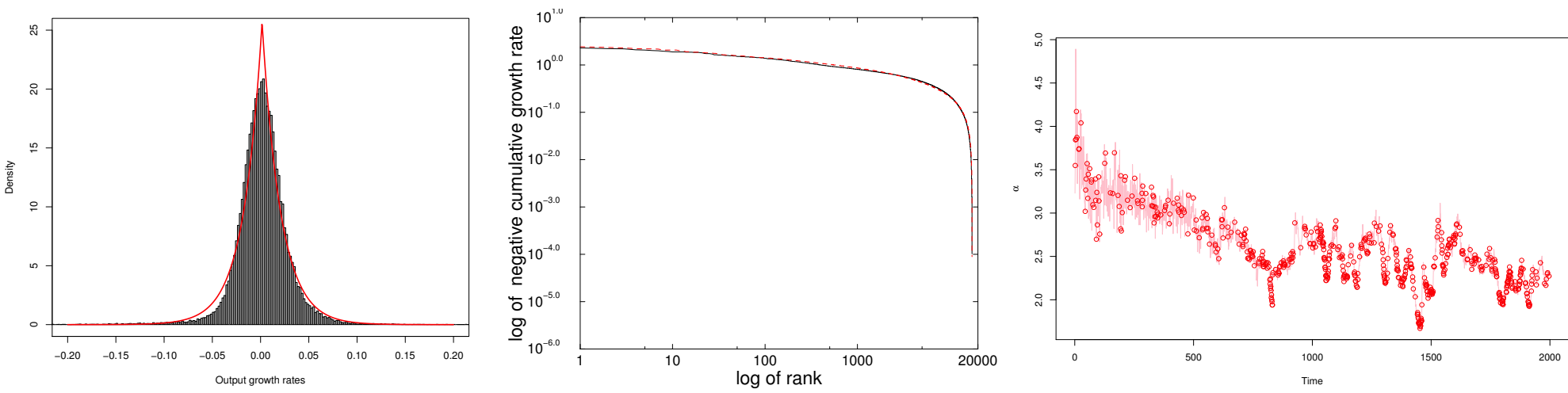

Figure 10: Probability density function of aggregate growth rates (left panel). Zipf plot of negative cumulative growth rate (black solid line) with Weibull best fit estimation (red dotted line) (center panel). Time series of the firms size power law exponent $\alpha$ (right panel). Colors are available on the web site version.

Let us now verify the model ability in reproducing financial stylized facts. Fig. 9 shows the zipf plots of loans, bad-debts and bankruptcies. In accordance with empirical studies (see Fujiwara, 2004; Delli Gatti et al., 2004) these distributions are skewed. Specifically, our results detect a power law distribution for loans and bad debts, with the Hill estimator of $\alpha$ equals to 1.17 and 1.25, respectively, while a Weibull distribution for bankruptcies, with the MLE of the shape parameter $\alpha=1.97$ and the scale parameter $\lambda=389.21$. It is worthy of note that, in our model, expansions are driven by credit granting, while contractions by bad debt and bankruptcies. These skewed distributions confirm that small and medium sized events dominate our system. Large events are relatively rare but, in the case of appearance, have a devastating effect on the economy (see Gabaix, 2011; Taleb, 2007, for a similar interpretation). Last but not least, we ana- 
lyze the effect of the interest rates on business cycles. In this regard, we find a negative correlation equal to -0.12 between interest rates and production, suggesting countercyclical real short term interest rates (see Aghion et al., 2015; Aguiar and Gopinath, 2007; Kaminsky et al., 2004; Neumeyer and Perri, 2005). In our model, in fact, interest rates first have a positive, significant, and robust impact on the economic growth then, during recessions, the effect revers and, via the financial accelerator mechanism, interest rates become harmful tools for propagating contagion.

The last part of this Appendix is devoted to business cycle facts. Left and center panel of Fig. 10 display the probability density function of aggregate growth rates and the zipf plot of negative cumulative growth rate, respectively. In line with empirical evidences (see Stanley et al., 1996; Bottazzi and Secchi, 2003, Di Guilmi et al., 2004), our model reproduces the Laplace distribution in the aggregate growth rate with the Maximum likelihood estimation of $\mu=0.0015$ and $b=0.019$ and the Weibull distribution in cumulative growth rate. Finally, the right panel of Fig. 10 shows that firms' size distribution shifts over the business cycle. Specifically, in accordance with Gaffeo et al. (2003) we observe an expansion in the firms' size during economic booms, while a decline during bursts.

Other important business cycle facts, such as excess volatility and volatility clustering in the output growth rate, have been already shown in Sec. 3.2. We refer the reader to that session for the empirical analysis.

\section{Appendix B}

\section{A sensitivity analysis on the model time scale}

In this appendix we investigate the main performances of our model by relaxing two hypotheses. Specifically, i) we create a desynchronization between the credit and the interbank market, so that the latter operates at higher time frequency; ii) we relax the assumption that agents update their strategies at each time step. In both of these experiments, we run our model 10 times for different values of the initial seed generating the pseudo-random numbers over a time span of $\mathrm{T}=2000$ periods. Moreover, all the agents' initialization parameters coincide with those presented in Sec. 3.

Let us start by describing how the point i) is implemented and its consequences on the model results.

This mismatch is generated by creating a desynchronization between firm and bank activation. Specifically, whereby banks are always operating, just a subgroup of firms are operating each period. Active companies are chosen randomly in such a way that only a percentage of firms re-update their production and credit choices each period. This naive mechanism generates a mismatch between firm and bank data frequency. In fact, financial institutions operating in the interbank market each period generate data at higher frequency than companies. The latter, in fact, which are not always active in the credit market, create lower-frequency data. Simulated results show an important difference 
compared with the baseline model where $100 \%$ of firms are always active. Specifically, by decreasing the number of active firms the average percentage of agents' rationing linearly decreases, as shown in the left panel of Fig. 11. Also the GDP decreases as the
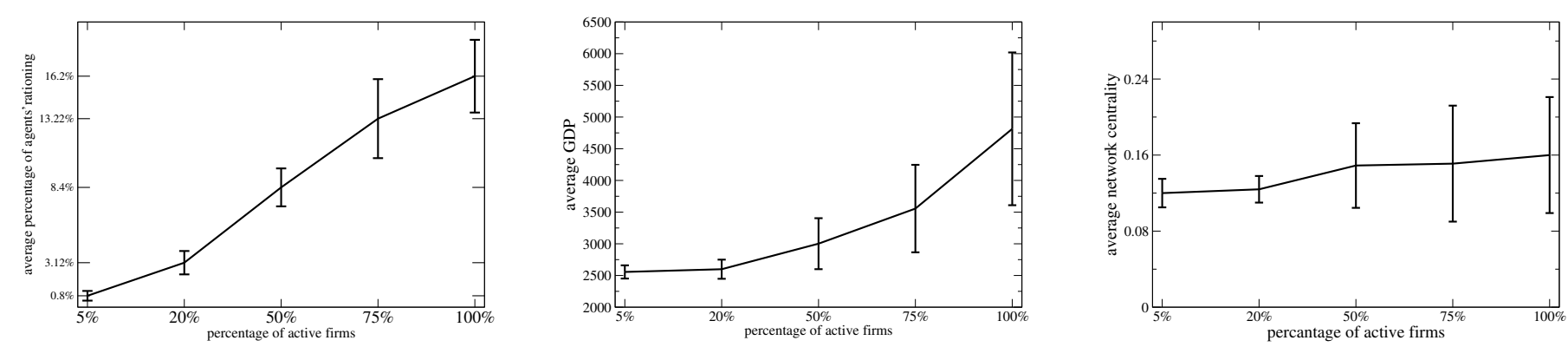

Figure 11: Average percentage of agents' rationing (left), average GDP (middle), and average network centrality (right), over all times and all simulations as a function of the percentage of active firms.

number of active companies decreases (see center panel of Fig. 11). However this decay is not linear. On the one hand, in fact, it is true that lower production is associated with the lower number of active companies. On the other hand, however, the rationing reduction associated with the smaller number of active firms partially compensates for the fall in the aggregate output. This second effect is clearly evident from the slope of the line shown in the center panel of Fig. 11, where we can observe a decreasing rate in the GDP fall by reducing the percentage of active firms. More interesting is the dynamics of the credit network centrality ${ }^{22}$ shown in the right panel of Fig. 11. As the reader can notice this network measure remains constant for low values of active companies. When the percentage of active companies exceeds $20 \%$, the network is on average more centralized. Furthermore, as shown in the figure, once exceeded this percentage, the centrality standard deviation significantly increases. This fact demonstrates a key element of our simulated system: the financial network crosses states of higher and lower centralization and the succession of these states strongly depend on the joint activation of the credit and the interbank market. When, in fact, only a few companies are active, credit relations often end up in the credit market. As the percentage of operating companies increases, instead, the need for banks to enter the interbank market to finance themselves increases substantially and this generates the well-known phenomenon of creation/destruction of the hub with the consequent centralization/decentralization of the network. Moreover, from the dynamical point of view the network evolution has the expected effects on business cycles. In fact, as we can notice by compering right and middle panel of Fig.11, a higher volatility in the centrality is associated with a higher volatility in the GDP. This finding reinforces our hypothesis on the correlation between GDP fluctuations and financial network centralization.

Finally, let us investigate how different time frequencies in the activation of the behav-

\footnotetext{
${ }^{22}$ Results on the interbank network centrality are omitted but very similar in spirit.
} 
ioral switching mechanism influence the model dynamics. To this end, we introduce a parameter able to model the probability to switch. Specifically, our agents re-update their strategies only if a random number uniformly distributed between zero and one is higher than a selected threshold $z$. Consequently, by increasing this threshold the switching probability decreases. In what follows, we study the main changes of our dynamics for $z=0 ; 0.2 ; 0.5 ; 0.723$. The simulated results, here presented, although referred just to the credit market -results on the interbank network are omitted as they are very similar in spirit-,confirm that our general findings are robust but with an important difference. At the micro level, results are quite obvious. In fact, as $z$ increases, the per-
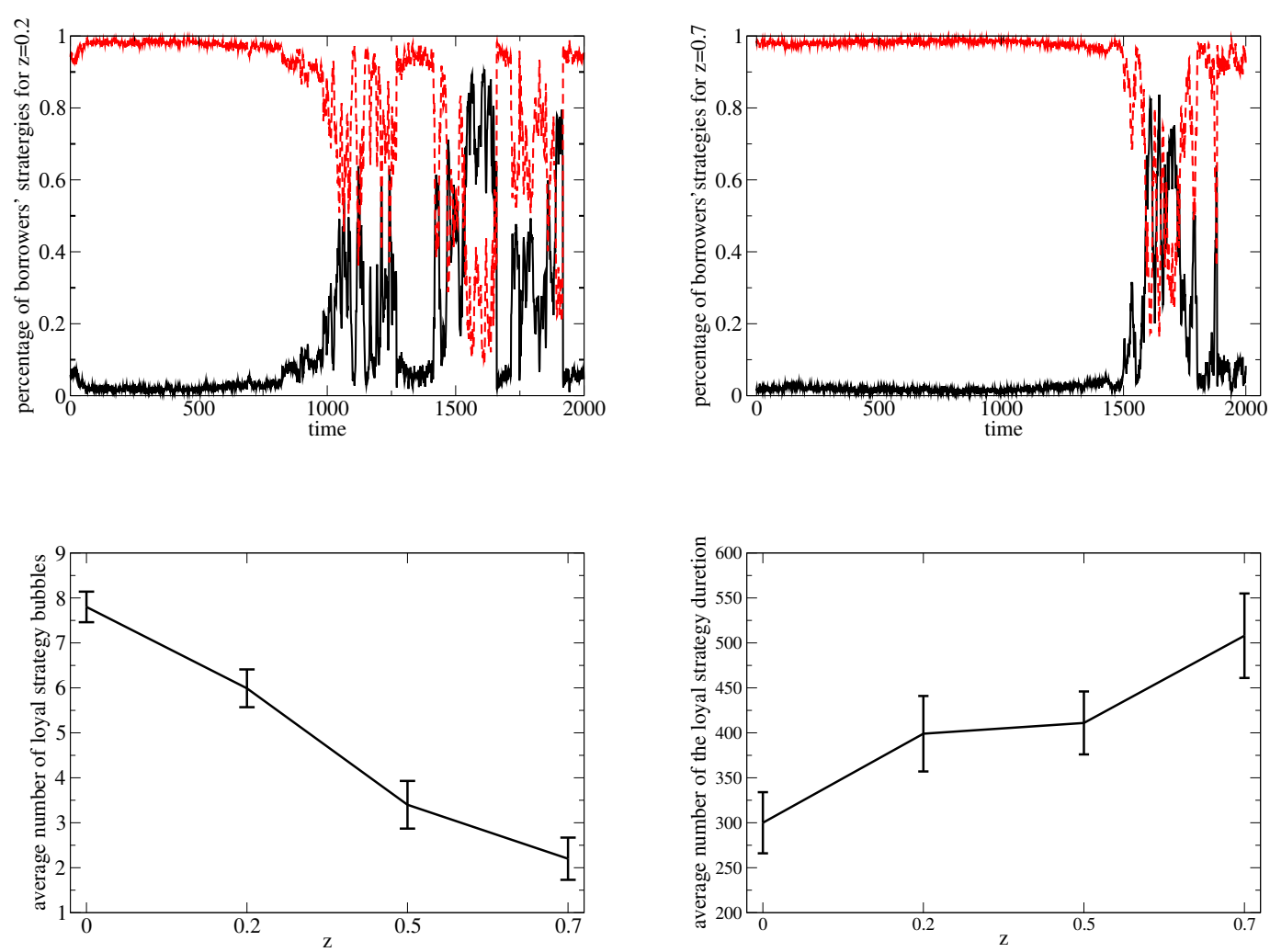

Figure 12: Percentage of loyal and shopper around borrowers, black solid line and red dotted line, respectively, for $z=0.2$ (top left panel) and $z=0.7$ (top right panel). Average number of loyal strategy bubbles (bottom left panel) and their duration (bottom right panel) as function of $\mathrm{z}$. The reported results just concern the credit market.

centage of agents switching from one strategy to the other one clearly decreases linearly. At the aggregate level, however, the dynamics is more interesting. In fact, by increasing $z$ two phenomena emerge. On the one hand, we observe a lower number of switching

\footnotetext{
${ }^{23}$ The value $z=0$, corresponding to the baseline case where strategies are updated each time period.
} 
corresponding to long periods of stable division between the two groups of strategies. On the other hand, once triggered the switching, we notice that this persists longer over time and generates a kind of stickiness which guarantees the supremacy of a strategy over the other for long time periods. These two aggregate phenomena are analyzed as follow. Given the simulated percentage of agents adopting the loyal strategy ${ }^{24}$ as shown in the black solid lines of Fig.12, we calculate the average number and duration of the time-series bubbles over time and simulations as a function of $z$. The average number of bubbles, calculated as the number of local maxima of the filtered series 25 gives us an idea on the switching frequency, while the average number of the bubbles' duration, calculated as the base of the triangle which includes the points from trough-to-trough of the filtered series, informs us on the strategy persistence. The results, reported in the bottom panels of Fig 12 , show that a reduction in the switching probability reduces the number of times in which the loyal strategy dominates but increases its duration.

It is worthy of note that the percentage of loyal agents drives the intensity of choice parameter $\beta$ which, in turn, determines the network evolution. Consequently, by varying $z$, the dynamics of the credit network centrality follows a similar pattern in term of average number and duration of the bubbles to that presented in the bottom panels of Fig 12. At this point the implication on the simulated business cycle are obvious: with the reduction of the switching probability recessions decrease but their duration increase 26 .

\footnotetext{
${ }^{24}$ Since the two strategies' percentages are reciprocal, the same results would be obtained using the simulated percentage of the shopping around strategy

${ }^{25}$ Given that the simulated time series are noisy, we extract the trend component by means of a Hodrick-Prescott filter We, then, use the detrended series to analyze the bubbles phases.

${ }^{26}$ Simulated results are omitted because similar to the ones shown in Fig 12.
} 


\section{References}

Acemoglu D., Ozdaglar A.E., and Tahbaz-Salehi A. Systemic risk and stability in financial networks. MIT Department of Economics Working Paper, 13-03, 2013. doi: https://ssrn.com/abstract=2211345orhttp://dx.doi.org/10.2139/ssrn.2211345.

Adrian T. and Shin H.S. Liquidity and leverage. Journal of Financial Intermediation, 19(3):418 - 437, 2010a.

Adrian T. and Shin H.S. The changing nature of financial intermediation and the financial crisis of 2007-2009. Annual Review of Economics, 2(1):603-618, 2010b.

Adrian T. and Shin H.S. Financial intermediary balance sheet management. Annual Review of Financial Economics, 3(1):289-307, 2011.

Affino M. Do interbank customer relationships exist? And how did they function in the crisis? Learning from Italy. Journal of Banking and Finance, 36(12):3163-3184, 2012.

Aghion P., Farhi E., and Kharroubi E. Liquidity and growth: the role of countercyclical interest rates. Working Paper 489, Bank for International Settlements, February 2015.

Aguiar M. and Gopinath G. Emerging market business cycles: The cycle is the trend. Journal of Political Economy, 115(1):69-102, 2007.

Aikman D., Haldane A.G., and Nelson B.D. Curbing the credit cycle. The Economic Journal, 125(585):1072-1109, 2015.

Albert R. and Barabási A.L. Statistical mechanics of complex networks. Reviews of modern physics, 74(1):47, 2002.

Amaral L.A.N., Buldyrev S.V., Havlin S., Leschhorn H., Maass P., Salinger M.A., Stanley H.E., and Stanley M.H.R. Scaling behavior in economics: I. empirical results for company growth. J. Phys. I France, 7(4):621-633, 1997.

Avery R.B. and Samolyk K.A. Bank consolidation and small business lending: The role of community banks. Journal of Financial Services Research, 25(2-3):291-325, 2004.

Axtell R.L. Zipf distribution of u.s. firm sizes. Science, 293(5536):1818-1820, 2001.

Bank for International Settlements (BIS). The international interbank market: A descriptive study. BIS Economic Papers, 8:, 1983, July.

Bargigli L. and Tedeschi G. Interaction in agent-based economics: A survey on the network approach. Physica A: Statistical Mechanics and its Applications, 399(Supplement C):1 - 15, 2014.

Bargigli L., di-Iasio G., Infante L., Lillo F., and Pierobon F. The multiplex structure of interbank networks. Quantitative Finance, 15(4):673-691, 2015. 
Bartelsman E., Scarpetta S., and Schivardi F. Comparative analysis of firm demographics and survival: evidence from micro-level sources in oecd countries. Industrial and Corporate Change, 14(3):365-391, 2005.

Bassetto M., Cagetti M., and De Nardi M. Credit crunches and credit allocation in a model of entrepreneurship. Review of Economic Dynamic, 18(1):53-76, 2015.

Battiston S., Delli Gatti D., Gallegati M., Greenwald B., and Stiglitz J.E. Credit chains and bankruptcy propagation in production networks. Journal of Economic Dynamics and Control, 31(6):2061 - 2084, 2007.

Battiston S., Delli Gatti D., Gallegati M., Greenwald B., and Stiglitz J.E. Liaisons dangereuses: Increasing connectivity, risk sharing, and systemic risk. Journal of Economic Dynamics and Control, 36(8):1121 - 1141, 2012a.

Battiston S., Delli Gatti D., Gallegati M., Greenwald B., and Stiglitz J.E. Default cascades: When does risk diversification increase stability? Journal of Financial Stability, 8(3):138 - 149, 2012b.

Berardi S. and Tedeschi G. From banks' strategies to financial (in) stability. International Review of Economics \& Finance, 47:255-272, 2017.

Berger A.N. and Black L.K. Bank size, lending technologies, and small business finance. Journal of Banking and Finance, 35(3):724 - 735, 2011. Australasian Finance Conference: Global financial crisis, international financial architecture and regulation.

Berger A.N. and Frame W.S. Small business credit scoring and credit availability. Journal of Small Business Management, 45(1):5-22, 2007.

Berger A.N. and Udell G.F. Relationship lending and lines of credit in small firm finance. The Journal of Business, 68(3):351-381, 1995.

Bernanke B. and Gertler M. Agency costs, net worth, and business fluctuations. The American Economic Review, pages 14-31, 1989.

Bernanke B., Gertler M., and Gilchrist S. The financial accelerator in a quantitative business cycle framework. Handbook of macroeconomics, 1:1341-1393, 1999.

Bianconi G. and Barabási A.L. Competition and multiscaling in evolving networks. EPL (Europhysics Letters), 54(4):436, 2001.

Bank for International Settlements BIS. Basel III: A global regulatory framework for more resilient banks and banking systems, 2010.

Boot A.W.A. Relationship banking: What do we know? Journal of Financial Intermediation, 9(1):7 - 25, 2000. ISSN 1042-9573.

Borio C. The financial cycle and macroeconomics: What have we learnt? Journal of Banking $\&$ Finance, 45(Supplement C):182 - 198, 2014. 
Boss M., Elsinger H., Summer M., and ThurnerS. Network topology of the interbank market. Quantitative Finance, 4(6):677-684, 2004.

Bottazzi G. and Secchi A. Why are distributions of firm growth rates tent-shaped? Economics Letters, 80(3):415 - 420, 2003.

Brock W.A. and Hommes C.H. A rational route to randomness. Econometrica: Journal of the Econometric Society, pages 1059-1095, 1997.

Brunnermeier M.K., Eisenbach T.M., and Sannikov Y. Macroeconomics with financial frictions: A survey. Working Paper 18102, National Bureau of Economic Research, 2012 .

Butler J, Giuliano P, and Guiso L. The Right Amount of Trust. Journal of the European Economic Association, 14(5):1155-1180, 2016.

Caccioli F., Catanach T.A., and Farmer J.D. Heterogeneity, correlations and financial contagion. Advances in Complex Systems, 15(supp02):1250058, 2012.

Canning D., Amaral L.A.N., Lee Y., Meyer M., and Stanley H.E. Scaling the volatility of gdp growth rates. Economics Letters, 60(3):335 - 341, 1998. ISSN 0165-1765.

Cao M. and Shi S. Screening, bidding, and the loan market tightness. Review of Finance, 5(1-2):21-61, 2001.

Carlstrom C.T. and Fuerst T.S. Agency costs, net worth, and business fluctuations: A computable general equilibrium analysis. The American Economic Review, 87(5): 893-910, 1997.

Catullo E., Grilli R., Palestrini A., and Gallegati M. Early warning indicators and macro-prudential policies: A credit network agent based model. Journal of Economic Interaction and Coordination, pages 1-35, 2017.

Chiarella C., Iori G., and Perelló J. The impact of heterogeneous trading rules on the limit order book and order flows. Journal of Economic Dynamics and Control, 33(3): 525-537, 2009.

Christiano L. and Ikeda D. Government Policy, Credit Markets and Economic Activity. NBER Working Papers 17142, National Bureau of Economic Research, Inc, 2011.

Clauset A., Shalizi C.R., and Newman M. Power-law distributions in empirical data. SIAM review, 51(4):661-703, 2009.

De Grauwe P., and Macchiarelli C. Animal spirits and credit cycles. Journal of Economic Dynamics and Control, 59, 95-117, 2015.

Delli Gatti D., Di Guilmi C., Gaffeo E., Giulioni G., Gallegati M., and Palestrini A. Business cycle fluctuations and firms' size distribution dynamics. Advances in Complex Systems, 07(02):223-240, 2004. 
Delli Gatti D., Di Guilmi C., Gaffeo E., Giulioni G., Gallegati M, and Palestrini A. A new approach to business fluctuations: heterogeneous interacting agents, scaling laws and financial fragility. Journal of Economic behavior $\mathcal{G}$ organization, 56(4):489-512, 2005 .

Delli Gatti D., Gaffeo E., Gallegati M., Giulioni G., Kirman A., Palestrini A., and Russo A. Complex dynamics and empirical evidence. Information Sciences, 177(5): $1204-1221,2007$.

Delli Gatti D., Gallegati M., Greenwald B., Russo A., and Stiglitz J.E. Business fluctuations and bankruptcy avalanches in an evolving network economy. Journal of Economic Interaction and Coordination, 4(195), 2009.

Delli Gatti D., Gallegati M., Greenwald B., Russo A., and Stiglitz J.E. The financial accelerator in an evolving credit network. Journal of Economic Dynamics and Control, 34(9):1627 - 1650, 2010.

Di Guilmi C., Gaffeo E., and Gallegati M. Empirical results on the size distribution of business cycle phases. Physica A: Statistical Mechanics and its Applications, 333 (Supplement C):325 - 334, 2004.

Dinger V. and Von-Hagen J. Does interbank borrowing reduce bank risk? Discussion Paper Series of SFB/TR 15 Governance and the Efficiency of Economic Systems,223 :2007.

Ferri P. and Minsky H.P. Market processes and thwarting systems. Structural Change and Economic Dynamics, 3(1):79-91, 1992.

Fujiwara Y. Zipf law in firms bankruptcy. Physica A: Statistical Mechanics and its Applications, 337(1):219 - 230, 2004.

Gabaix X. The granular origins of aggregate fluctuations. Econometrica, 79(3):733-772, 2011.

Gabaix X., Gopikrishnan P., Plerou V., and Stanley H.E. Institutional investors and stock market volatility. The Quarterly Journal of Economics, 121(2):461-504, 2006.

Gaffeo E., Gallegati M., and Palestrini A. On the size distribution of firms: additional evidence from the g7 countries. Physica A: Statistical Mechanics and its Applications, 324(1):117 - 123, 2003.

Gaunersdorfer A., Hommes C.H., and Wagener F. Bifurcation routes to volatility clustering under evolutionary learning. Journal of Economic Behavior \& Organization, 67(1):27-47, 2008.

Geanakoplos J. The leverage cycle. In NBER Macroeconomics Annual 2009, Volume 24, pages 1-65. National Bureau of Economic Research, Inc, 2010. 
Gertler M. and Kiyotaki N. Financial intermediation and credit policy in business cycle analysis. volume 3 of Handbook of Monetary Economics, pages 547 - 599. Elsevier, 2010 .

Gertler M., and Williamson S. Introduction to the special issue on money, credit, and financial frictions. Review of Economic Dynamics, 18(1):1-2, 2015.

Glasserman P. and Young H.P. How likely is contagion in financial networks? Journal of Banking and Finance, 50(Supplement C):383 - 399, 2015.

Greenwald B.C. and Stiglitz J.E. Financial market imperfections and business cycles. Quarterly Journal of Economics, 108(1), 1993.

Grilli R., Tedeschi G., and Gallegati M. Bank interlinkages and macroeconomic stability. International Review of Economics \& Finance, 34:72 - 88, 2014.

Grilli R., Tedeschi G., and Gallegati M. Markets connectivity and financial contagion. Journal of Economic Interaction and Coordination, 10(2):287-304, 2015.

Grilli R., Iori G., Stamboglis N., and Tedeschi G. A networked economy: A survey on the effect of interaction in credit markets. In Gallegati M., Palestrini A., and Russo A., editors, Introduction to Agent-Based Economics, pages 229 - 252. Academic Press, 2017.

Hémous D. and Olsen M. Long-term Relationships: Static Gains and Dynamic Inefficiencies. Journal of the European Economic Association, jvx019, 2017. doi: http://dx.doi.org/10.1093/jeea/jvx019.

Hommes C.H. Heterogeneous agent models in economics and finance. Handbook of computational economics, 2:1109-1186, 2006.

Ijiri Y. and Simon H. Skew distributions and the sizes of business firms. Ed: North Holland, New York., 1977.

Iori G., Jafarey S., and Padilla F.G. Systemic risk on the interbank market. Journal of Economic Behavior and Organization, 61(4):525 - 542, 2006.

Iori G., De Masi G., Precup O.V., Gabbi G., and Caldarelli G. A network analysis of the italian overnight money market. Journal of Economic Dynamics and Control, 32 (1):259-278, 2008.

Jordà O., Schularick M., and Taylor A.M. Leveraged bubbles. Journal of Monetary Economics, 76(Supplement):S1 - S20, 2015.

Kaminsky G.L., Reinhart C.M., and Vègh C.A. When it rains, it pours: Procyclical capital flows and macroeconomic policies. NBER Macroeconomics Annual, 19:11-53, 2004 . 
Kiyotaki N. and Moore J. Credit cycles. Journal of Political Economy, 105(2):211-248, 1997.

Kukacka J. and Barunik J.. Estimation of financial agent-based models with simulated maximum likelihood. Journal of Economic Dynamics and Control, 85(Supplement C): $21-45,2017$.

Lageras A. and Seim D. Strategic complementarities, network games and endogenous network formation. International Journal of Game Theory, 45(3):497-509, 2016.

Lenzu S. and Tedeschi G. Systemic risk on different interbank network topologies. Physica A: Statistical Mechanics and its Applications, 391(18):4331-4341, 2012.

Lux T and Marchesi M. Volatility clustering in financial markets: a microsimulation of interacting agents. International journal of theoretical and applied finance, 3(04): 675-702, 2000.

Mayer C. New issues in corporate finance. European Economic Review, 32(5):1167 $1183,1988$.

Minsky H.P. Longer waves in financial relations: Financial factors in the more severe depressions. The American Economic Review, 54(3):324-335, 1964.

Mishkin F.S. How should we respond to asset price bubbles? Banque de France Financial Stability Review-Valuation and Financial Stability, (12):65-74, 2008.

Montagna M., and Kok C. Multi-Layered Interbank Model For Assessing Systemic Risk. ECB Working Paper, 1944:, 2016.

Neumeyer P.A. and Perri F. Business cycles in emerging economies: the role of interest rates. Journal of Monetary Economics, 52(2):345 - 380, 2005.

Ongena S. and Smith D.C. Bank relationships: a review. In Zenios S.A. and Harker P., editors, Performance of Financial Institutions, pages 221 - 258. Cambridge University Press, Cambridge), 2000.

Petersen M.A. and Rajan R.G. The benefits of lending relationships: Evidence from small business data. The Journal of Finance, 49(1):3-37, 1994.

Petersen M.A. and Rajan R.G. The effect of credit market competition on lending relationships. The Quarterly Journal of Economics, 110(2):407-443, 1995.

Presbitero A.F., Udell G.F., and Zazzaro A. The home bias and the credit crunch: A regional perspective. Journal of Money, Credit and Banking, 46(s1):53-85, 2014.

Pushkin D.O. and Aref H. Bank mergers as scale-free coagulation. Physica A: Statistical Mechanics and its Applications, 336(3):571 - 584, 2004. 
Rajan R.G. Why bank credit policies fluctuate: A theory and some evidence*. The Quarterly Journal of Economics, 109(2):399-441, 1994.

Recchioni M.C., Tedeschi G., and Gallegati M. A calibration procedure for analyzing stock price dynamics in an agent-based framework. Journal of Economic Dynamics and Control, 60(Supplement C):1 - 25, 2015.

Stanca L. and Gallegati M. The dynamic relation between financial positions and investment: evidence from company account data. Industrial and Corporate Change, 8 (3):551-572, 1999 .

Stanley M.H.R., Amaral L.A.N., Buldyrev S.V., Havlin S., Leschhorn H., Maass P., Salinger M.A., and Stanley H.E. Scaling behavior in the growth of companies. Nature, 379:804-806, 1996.

Strahan P.E. and Weston J.P. Small business lending and the changing structure of the banking industry. Journal of Banking and Finance, 22(6):821 - 845, 1998.

Taleb N.N. The Black Swan: The Impact of the Highly Improbable. Ed: Penguin Books, 2007.

Tedeschi G., Iori G., and Gallegati M. The role of communication and imitation in limit order markets. The European Physical Journal B, 71(4):489, 2009.

Tedeschi G., Iori G., and Gallegati M. Herding effects in order driven markets: The rise and fall of gurus. Journal of Economic Behavior \& Organization, 81(1):82-96, 2012a.

Tedeschi G., Mazloumian A., Gallegati M., and Helbing D. Bankruptcy cascades in interbank markets. PloS one, 7(12):e52749, 2012b.

Tesfatsion L. Web site on validation of ace. http://www.econ.iastate.edu/tesfatsi/empvalid.htm, 2017.

Tedeschi G., Vitali S., and Gallegati M. The dynamic of innovation networks: a switching model on technological change. Journal of Evolutionary Economics, 24(4):817- 834, 2014 .

Vidal-Tomas D., Tedeschi G., and Ripolles J. The desertion of rich countries and the mutual support of the poor ones: Preferential lending agreements among the PIGS. Finance Research Letters, doi.org/10.1016/j.frl.2019.08.003:, 2019.

Zipf K.G. Human behavior and the principle of least effort. Ed: Addison-Weslay, Reading, MA., 1949. 